\title{
Operational Soil Moisture from ASCAT in Support of Water Resources Management
}

\author{
Khidir Abdalla Kwal Deng 1,2, Salim Lamine ${ }^{3} \mathbb{D}$, Andrew Pavlides 4 , \\ George P. Petropoulos $4,5, *(\mathbb{D})$, Prashant K. Srivastava ${ }^{6}\left(\mathbb{D}\right.$, Yansong Bao ${ }^{1,2}$, \\ Dionissios Hristopulos 4 (D) and Vasileios Anagnostopoulos ${ }^{7}$
}

1 Collaborative Innovation Center on Forecast and Evaluation of Meteorological Disasters, Nanjing University of Information Science \& Technology, Nanjing 210044, China; khidir14332@yahoo.com (K.A.K.D.); ysbao@nuist.edu.cn (Y.B.)

2 School of Atmospheric Physics, Nanjing University of Information Science and Technology, Nanjing 210044, China

3 Faculty of Natural Sciences, Life and Earth Sciences, University Akli Mohand Oulhadj of Bouira, Bouira 10000, Algeria; salim.lamine@gmail.com

4 School of Mineral Resources Engineering, Technical University of Crete, 73100 Crete, Greece; apavlides24@yahoo.com (A.P.); dionisi@mred.tuc.gr (D.H.)

5 Department of Soil \& Water Resources, Institute of Industrial \& Forage Crops, Hellenic Agricultural Organization "Demeter", 41335 Larisa, Greece

6 Institute of Environment and Sustainable Development and DST-Mahamana Centre for Excellence in Climate Change Research, Banaras Hindu University, Varanasi 221005, India; prashant.just@gmail.com

7 Distributed and Knowledge Management Systems Lab, National Technical University of Athens, 15780 Athens, Greece; fithis2001@gmail.com

* Correspondence: petropoulos.george@gmail.com; Tel.: +30-28210-37642

Received: 9 February 2019; Accepted: 5 March 2019; Published: 9 March 2019

\begin{abstract}
This study provides the results of an extensive investigation of the Advanced Scaterometter (ASCAT) surface soil moisture global operational product accuracy across three continents (United States of America (USA), Europe, and Australia). ASCAT predictions of surface soil moisture were compared against near concurrent in situ measurements from the FLUXNET observational network. A total of nine experimental sites were used to assess the accuracy of ASCAT Surface Soil Moisture (ASCAT SSM) predictions for two complete years of observations $(2010,2011)$. Results showed a generally reasonable agreement between the ASCAT product and the in situ soil moisture measurements in the $0-5 \mathrm{~cm}$ soil moisture layer. The Root Mean Square Error (RMSE) was below $0.135 \mathrm{~m}^{3} \mathrm{~m}^{-3}$ at all of the sites. With a few exceptions, Pearson's correlation coefficient was above $45 \%$. Grassland, shrublands, and woody savanna land cover types exhibited satisfactory agreement in all the sites analyzed (RMSE ranging from 0.05 to $0.13 \mathrm{~m}^{3} \mathrm{~m}^{-3}$ ). Seasonal performance was tested, but no definite conclusion can be made with statistical significance at this time, as the seasonal results varied from continent to continent and from year to year. However, the satellite and in situ measurements for Needleleaf forests were practically uncorrelated $(R=-0.11$ and -0.04$)$. ASCAT predictions overestimated the observed values at all of the sites in Australia. A positive bias of approximately $0.05 \mathrm{~m}^{3} \mathrm{~m}^{-3}$ was found with respect to the observed values that were in the range $0-0.3 \mathrm{~m}^{3} \mathrm{~m}^{-3}$. Better agreement was observed for the grassland sites in most cases (RMSE ranging from 0.09 to $0.10 \mathrm{~m}^{3} \mathrm{~m}^{-3}$ and $\mathrm{R}$ from 0.46 to 0.90 ). Our results provide supportive evidence regarding the potential value of the ASCAT global operational product for meso-scale studies and the relevant practical applications. A key contribution of this study is a comprehensive evaluation of ASCAT product soil moisture estimates at different sites around the globe. These sites represent a variety of climatic, environmental, biome, and topographical conditions.
\end{abstract}


Keywords: surface soil moisture; earth observation; operational products; ASCAT; validation

\section{Introduction}

Information regarding the temporal and spatial variation of the Surface Soil Moisture (SSM) is of crucial importance for an understanding of hydrological processes. It governs energy fluxes by controlling the exchange and partitioning of water over land. It also plays a significant role in predictions of the weather climate from the regional scale to the global scale [1]. At the global scale, accurate SSM measurements are fundamental in improving numerical weather prediction [2] and hydrological modeling [3,4]. Accurate information on SSM is important in the simulations and future projections of climate variables, such as temperature [5], and also in predicting extreme events, such as floods [6]. SSM accurate temporal and spatial characterization is also essential for agriculture and irrigation management practices, particularly in arid and semiarid regions [7]. In addition, information on this parameter is important in biodiversity and ecosystems management $[8,9]$. Moreover, it influences the water cycle through evapotranspiration [10] and precipitation [11]. Land use and land cover are factors that influence soil moisture spatiotemporal variability and can alter soil hydraulic properties because of changes in the porosity and structure of the soil [12]. Seasonal changes also control the water exchange between that land surface and the atmosphere and hence influence the behavior of soil moisture [13]. On this basis, to improve the methods of water resources management, climate modeling requires an accurate representation of SSM at a high temporal and spatial resolution [14].

Soil moisture can be directly measured using appropriate ground instrumentation, and there is a wide range of options for this purpose [15]. Yet, direct measurement has been a difficult and it is often a challenging task given the heterogeneous nature of soil moisture in both time and space (due to variability in climate/weather, snow, topography, vegetation, land use, water table depth, and soil type). Generally, in situ observations cannot fully characterize the spatial and temporal variability of soil moisture at large scale [16]. Moreover, it is impractical to deploy dense network stations all over the world. Alternatively, large scale monitoring soil moisture at a range of spatial and temporal resolution of different land cover types can only rely on remote sensing from space-borne approaches [17]. Remote sensing techniques have the advantage of simultaneously achieving satisfactory sampling frequency and global coverage. They also show a direct sensitivity to the SSM at different microwave bands [18]. In spite of efforts to model global soil moisture at high temporal and spatial scales, practically, at the current maturity of technology and computational resource, global soil moisture measurements can only be attained through satellite remote sensing [19]. Indeed, advances in Earth Observation (EO) over the past decades have been effectively applied to measure SSM, resulting in the global availability of this parameter at an increased temporal and spatial resolution. Researchers have exerted great efforts on the development of soil moisture retrieval algorithms for various microwave remote sensing satellite/sensors.

Currently, several satellite soil moisture operational products are available from microwave, optical, and thermal sensors (e.g., [20]. One of the most widely used ones includes that from the Soil Moisture Active and Passive (SMAP) satellite, which was launched in January 2015 starting from April 2015 with $\sim 36 \mathrm{~km}^{2} / 2$-day spatial/temporal resolution [21]. The Advanced Microwave Scanning Radiometer (AMSR-2) on the GCOM-W1 (Global Change Observation Mission-Water) satellite (C- and X-band radiometers), starting from July 2012 with $\sim 25 \mathrm{~km}^{2} / 1$-day spatial/temporal resolution [22]. The European Space Agency (ESA) Soil Moisture and Ocean Salinity (SMOS) satellite product (L-band radiometer), starting from January 2010 with $\sim 50 \mathrm{~km}^{2} / 2$-day spatial/temporal resolution [23]. Advanced Scaterometter (ASCAT) onboard Metop-A and Metop-B satellites (C-band scatterometer) starting from January 2007 with $\sim 25 \mathrm{~km}^{2} / 1$-day spatial/temporal resolution [24]. Additionally, there are efforts dedicated to the merging of the passive and active soil moisture products 
under the ESA (European Space Agency) Climate Change Initiative (CCI) soil moisture product (CCI $\mathrm{SM})$, in an attempt to generate a long term global scale soil moisture record $[25,26]$ and the Microwave Radiation Imager onboard Feng Yun [24,27-30].

A fundamental aspect is related to the error characterization of the soil moisture products. It includes two aspects: one is that the result of the validation can be used as a feedback to algorithm developers for further improvements in the retrieval of SSM; the other is to facilitate the potential users to understand the status of the product, such as the accuracy, magnitude, and the uncertainties of the remote sensed products. Both are very important as they help in better understanding their potential use for practical applications (e.g., [20,31]). Additionally, long term soil moisture datasets are been used in hydrological and land surface modeling assimilation [26,32]. Several studies have been dedicated to assessing the accuracy specifically of the ASCAT soil moisture product by either comparing it against model simulations or ground measurements from networks that operated from around the world [33-37]. Yet, to our knowledge, there is not too many such studies performed in Europe [27,38,39], the United States [40] and Australia [22]. Consequently, a better global understanding of the ASCAT SSM product accuracy is required.

In light of the above, this study aims at evaluating the accuracy of ASCAT global operational soil moisture product at different sites globally representative of a variety of climatic, environmental, biome, and topographical conditions. For this purpose, in situ measurements from the global validated FLUXNET ground observational network acquired nearly concurrently to ASCAT overpass have been utilized. The appraisal of the product accuracy was investigated herein with respect to seasons and land use/land cover patterns. Such assessment is an important step for successful hydrological modeling, agriculture, and water resource management, and it can provide importance assistance in policy and decision making.

\section{Experimental Set up}

\subsection{In Situ Measurements}

In situ SSM measurements were acquired from selected sites that were representative of different ecosystems that belong to the FLUXNET observational network. A total of nine experimental sites were used in this study. FLUXNET is the largest global in situ measurements network that coordinates regional and global analysis of micrometeorological fluxes and ancillary parameters [41]. At those sites, soil moisture content is measured in at least two depths (surface and root zone) at 30-min frequencies while using standardized instrumentation across sites. All the collected data are quality-controlled, gap-filled, and standard procedures for error corrections are prescribed. All data that were used in our study were readily available and obtained at no cost from the FLUXNET database (http://fluxnet.ornl.gov/obtain-data) at Level 2 processing, to allow for consistency and interoperability across all sites investigated. This processing level includes the originally acquired in situ data, from which any erroneous data (e.g., ones caused by obvious instrumentation error) have been removed. This enables the uniform measurement comparisons between sites and datasets. In our study, in situ data for the complete years 2010 and 2011 were acquired from nine experimental sites of varying environmental and ecosystem conditions. These nine sites include three sites in Europe, United States, and Australia, which are representative of open shrubland, grassland, and evergreen needleleaf. In this study, the sites were only selected where continuous long term datasets are available. Another important factor during the selection of sites is homogeneity in the land cover type. To avoid any mixed pixel effects on the overall performance, satellite pixels are chosen over the FLUXNET towers, having the largest homogenous land cover. In addition, the sites proposed are a complementary selection as compared to other validation studies of the same product. Site names, together with their main characteristics, are listed in Table 1. All in situ data were obtained from the FLUXNET website and, where possible, verified by the site manager. 
Table 1. Geographical location and land cover type for the FLUXNET flux tower sites that are used in our study by continent and country.

\begin{tabular}{|c|c|c|c|}
\hline Site Name \& ID & $\begin{array}{l}\text { Geographic } \\
\text { Coordinates }\end{array}$ & Country & Land Cover \\
\hline \multicolumn{4}{|c|}{ EUROPE } \\
\hline Aguamarga (AGU) & $36.8347 / 2.2511$ & Spain & Open shrubland $(\mathrm{OSH})$ \\
\hline Liano de los Juanes (LJU) & $36.9266 /-2.7521$ & Spain & Open shrubland (OSH) \\
\hline Renon (REN) & $46.5869 / 11.4337$ & Italy & $\begin{array}{l}\text { Evergreen Needleleaf } \\
\text { Forests (ENF) }\end{array}$ \\
\hline \multicolumn{4}{|c|}{ USA } \\
\hline Tonzi Ranch (TON) & $38.4316 /-120.9660$ & USA & Woody Savannas (WSA) \\
\hline Vaira Ranch- Ione (VAR) & $38.4133 /-120.9507$ & USA & Grassland (GRA) \\
\hline $\begin{array}{l}\text { Walnut Gulch Lucky Hills } \\
\text { Shrub (US_WHS) }\end{array}$ & $31.7438 /-110.0522$ & USA & Open shrubland $(\mathrm{OSH})$ \\
\hline \multicolumn{4}{|c|}{ Australia } \\
\hline Daly River Savanna (DPA) & $-14.0633 / 131.3181$ & Australia & Grassland (GRA) \\
\hline Howard Springs (HS) & $-12.4943 / 131.1523$ & Australia & Woody Savannas (WSA) \\
\hline Sturt Plains (STP) & $-17.1507 / 133.3502$ & Australia & Grassland (GRA) \\
\hline
\end{tabular}

\subsection{Satellite Datasets}

Satellite soil moisture was acquired from the ASCAT sensor, onboard the MetOp satellite platform. ASCAT is a microwave real aperture radar sensor that measures the radar backscatter at C-band in a vertical Polarization [31]. Measurements are taken on both sides of the sub-satellite track over two $550 \mathrm{~km}$ wide swaths, from an $817 \mathrm{~km}$ height orbit; there are 14 orbit revolutions per day, resulting in a global coverage being achieved in $~ 1.5$ days. Backscatter measurements from this sensor are transformed into SSM estimates with the TU Wien method that was originally developed for the ERS AMI WS instruments by Wagner et al. [42] and improved by Naeimi et al. [43]. EUMETSAT provides this operational dataset in near real time [31] and the Vienna University of Technology, Austria provides it as a reprocessed archive. It has a spatial resolution of $25 \mathrm{~km}$ grids and it is produced by a means of the TU Wien algorithm. Each pixel value represents a relative value $(0 \%$ and $100 \%)$ of soil moisture with respect to the driest and wettest condition registered for that pixel during the calibration phase of the TU Wien algorithm. The algorithm is based on a change in the detection approach, which assumes that the soil moisture is linearly related to backscattering (in dB units), and that the temporal change of surface roughness, canopy structure, and vegetation biomass occur at a longer temporal scale than soil moisture change. Thus, in time, SSM variation can be detected. The change detection approach is an empirical approach that looks at the difference in SSM as a function of time [42].

\section{Methods}

The quality of the in situ data was first assessed by the information acquired from the in situ data providers, where only the quality-passed data were used in further analysis. The pre-processed in situ soil moisture data values that corresponded to the date/time of the satellite overpasses were extracted (Excel Macro VBA) and then assigned to point shapefiles of the study site (Tabular join in ArcMap 10.2); the shapefiles were imported on the top of the pre-processed ASCAT image pixels in the BEAM VISAT and ASCAT toolbox. Using the correlation tool, in situ soil moisture was matched against the ASCAT soil moisture unit of the pixel containing the site point. These pixels were then extracted to Microsoft Excel for further analysis and comparisons against the in situ data. In a few cases, the in situ soil moisture data had an assigned value of " 0 " SSM, or the satellite data had an assigned value of " 0 " SSM. Data values of " 0 " were removed from the dataset if the difference between the in situ and ASCAT measurements were above $0.1 \mathrm{SSM}$, as they are considered to be instrumental errors. 
Agreement between the ASCAT-predicted soil moisture and the corresponding in situ data was evaluated based on direct point by point comparisons of the two datasets. Several statistical metrics were used to evaluate the agreement between the compared datasets, which have already been used in other similar studies (e.g., [31,44]). Those included the Root Mean Square Error (RMSE, Equation (2)), the Pearson's correlation coefficient (R), Spearman's correlation coefficient (Rs) (assesses the correlation between the rank of each value), the Mean Error (ME, Equation (1)) or Bias, and the Standard Deviation or Scatter (Equation (3)). The Spearman's correlation coefficient was used in this study to assess the monotonic relationship between the in situ data and ASCAT products. The confidence intervals for the estimated coefficients of the linear model (slope and Intercept) were examined. They are represented in the figures of this research wherever applicable with green dashed lines. If the range of the $95 \%$ confidence interval is very wide, which implies that the linear correlation is weak, the regression line is not shown. A detailed description of the statistical metrics can be found in Silk (1979), Burt and Barber (1996), and Willmott (1982). These statistical metrics have also been previously used in analogous validation experiments of relevant operational products [15].

$$
\begin{gathered}
E=\frac{1}{n} \sum_{i=1}^{n}\left(y_{i}-x_{i}\right) \\
\text { RMSE }=\sqrt{\frac{1}{n} \sum_{i=1}^{n}\left(y_{i}-\overline{x_{i}}\right)^{2}} \\
\text { Scatter }=\sqrt{\frac{\sum_{i=1}^{n}\left(y_{i}-\overline{x_{i}}\right)^{2}}{n}}
\end{gathered}
$$

Additional analysis explored the agreement between the satellite-derived and in situ SSM as a function of land cover type and seasonality. For analysis by land cover type, agreement was evaluated for nine sites, which are inclusive of four different land cover types: ES_AGU, ES_LJU and US_WGH—open shrubland, IT_REN—evergreen needleleaf forest, US_VAR, AU_DPA and AU_STP_grasslands, AU_HOW and USA_TON—woody savannas. Similarly, agreement was also evaluated for the four seasons, spring (March-May \September-November), summer (June-August $\backslash$ December-February), autumn (September-November $\backslash$ March-May), and winter (December-February $\backslash$ June-August). Seasons in the Southern hemisphere are given their correct calendar dates. Direct point-by-point comparisons were performed at every in situ station to evaluate the statistical agreement for each threshold. Analysis was independently performed for each scenario, for both 2010 and 2011.

\section{Results}

In this section, the results of each of the study locations are analyzed. For each group of sites that belong to a specific continent, an analysis into how the soil moisture product performed over different land covers, both seasonally and annually is presented. Such information can reveal the temporal behavior of the observed and estimated soil moisture during the entire period. The key results from the ASCAT product and the corresponding in situ soil moisture in all nine experimental sites with varying land use and land cover in 2010 and 2011 are presented in Tables 2-7 and Figures 1-9. As shown in the results, in all sites the RMSE was low (around $0.1 \mathrm{~m}^{3} \mathrm{~m}^{-3}$ ), suggesting satisfactory product accuracy. In most cases, the correlation coefficient was moderate (above 50\%). Notably, the validation measures for 2011 underperformed those of 2010.

A comparison between in situ and ASCAT SSM in shrublands shows low to very low RMSE (below $0.1 \mathrm{~m}^{3} \mathrm{~m}^{-3}$ ) and mediocre correlation (between 35\% and 50\%) coefficient for both of the years. Grasslands perform well in 2010 with low RMSE and a correlation coefficient above $65 \%$. Yet, the performance decreased in 2011 with an RMSE above $0.1 \mathrm{~m}^{3} \mathrm{~m}^{-3}$ and correlation coefficient dropping to 35\% in AU_STP. Woody Savannas present a moderately high RMSE at both sites for 
both of the years $\left(0.11-0.12 \mathrm{~m}^{3} \mathrm{~m}^{-3}\right.$, with one case at $\left.0.135 \mathrm{~m}^{3} \mathrm{~m}^{-3}\right)$. The correlation coefficient is high (between 66\% and 74\%), except for US_TON2011 (RMSE 0.135, R 0.393). Finally, the agreement was worse for the needleleaf forests with an RMSE that was slightly above $0.1 \mathrm{~m}^{3} \mathrm{~m}^{-3}$, but very low correlation coefficient. Furthermore, the coefficients for the slope and intercept for IT_REN exhibited wide confidence intervals (at 95\% confidence) for both 2010 and 2011. Thus, the ASCAT and in situ measurements are essentially uncorrelated for IT_REN sites.

Tables 3, 5 and 7 present the results of the seasonal analysis over a two-year period (2010 and 2011) for all three continents. As such, there are six representations for each season (three sites for two years). Winter presents the greatest variation in performance with some of the highest and lowest validation measures (RMSE ranging from 0.076 to $0.140 \mathrm{~m}^{3} \mathrm{~m}^{-3}$ and $\mathrm{R}$ ranging between $21 \%$ to $92 \%$ ). For autumn, the RMSE for 2010 is relatively good (between 0.08 to $0.11 \mathrm{~m}^{3} \mathrm{~m}^{-3}$ ), but 2011 autumn gives high RMSE (above $0.12 \mathrm{~m}^{3} \mathrm{~m}^{-3}$ in all cases). The Pearson's $\mathrm{R}$ is adequate in Europe and United States of America (USA) (above 63\%) and it has a slightly higher value in 2011. In Australia, a correlation coefficient above $53 \%$ was obtained for both years. In most cases, spring has relatively high RMSE (between 0.10 to $0.13 \mathrm{~m}^{3} \mathrm{~m}^{-3}$ ), with the exception of spring 2010 in Australia. There is high variation in the correlation coefficient for the spring period, with values that range from $28 \%$ to $75 \%$. The results for the summer period are similar with those of the spring period, if a little worse, with RMSE values that are in the range of 0.074 to $0.160 \mathrm{~m}^{3} \mathrm{~m}^{-3}$ and $\mathrm{R}$ between $28 \%$ and $62 \%$.

\subsection{Europe}

Table 2 and Figures 1 and 2 summarize the results from the comparisons of SSM between ASCAT and in situ. Both for the individual sites and for the combined data from all sites, the bias of the ASCAT measurements is low when compared to the range of the observed values. In the combined comparison, with 1788 points, the bias is $0.005 \mathrm{~m}^{3} \mathrm{~m}^{-3}$, while the values of in situ SSM range from 0 to $0.5 \mathrm{~m}^{3} \mathrm{~m}^{-3}$. In general, the ASCAT predictions show a mild RMSE (ranging between 0.82 and $1.06 \mathrm{~m}^{3} \mathrm{~m}^{-3}$ ) and also a generally unsatisfactory correlation coefficient. In contrast, the in situ and ASCAT measurements for the needleleaf forests are uncorrelated. The coefficients for the slope and intercept for IT_REN exhibited wide confidence intervals (at 95\% confidence) for both 2010 and 2011. As such, the values for these parameters could not be estimated with statistical confidence. Thus, the ASCAT and in situ measurements are essentially uncorrelated for REN sites.

Table 2. Comparison between satellite (ASCAT $25 \mathrm{Km}$ ) and observed Surface Soil Moisture (SSM) at the validation sites in EUROPE based on land cover type for 2010 and 2011. Slope and Intercept for REN are omitted due to lack of definite correlation.

\begin{tabular}{cccccccc}
\hline Measure & AGU 2010 & AGU 2011 & LJU 2010 & LJU 2011 & REN 2010 & REN 2011 & All Sites \\
\hline ME (Bias) & -0.004 & -0.021 & 0.001 & -0.042 & 0.051 & 0.031 & 0.005 \\
MAE & 0.079 & 0.068 & 0.076 & 0.085 & 0.085 & 0.086 & 0.080 \\
RMSE & 0.096 & 0.082 & 0.094 & 0.105 & 0.106 & 0.102 & 0.099 \\
R & 0.457 & 0.361 & 0.441 & 0.379 & -0.116 & -0.038 & 0.410 \\
Rs & 0.405 & 0.308 & 0.334 & 0.408 & -0.149 & -0.037 & 0.407 \\
Scatter & 0.096 & 0.079 & 0.094 & 0.096 & 0.093 & 0.097 & 0.098 \\
Slope & 0.220 & 0.357 & 0.311 & 0.394 & - & - & 0.463 \\
Intercept & 0.108 & 0.054 & 0.142 & 0.078 & - & - & 0.106 \\
N & 252 & 220 & 356 & 293 & 334 & 333 & 1788 \\
\hline
\end{tabular}

\subsubsection{Land Use and Land Cover Comparisons}

Table 2 and Figures 1 and 2 summarize the SSM comparisons between the ASCAT product and the corresponding in situ values at the different experimental sites in Europe varying land use and land cover in 2010 and 2011. It shows various performances that are associated to land surface types when data for both years plotted combined or individual sites. It can be noted that, over the evergreens 
forest, there is no correlation between in situ and ASCAT soil moisture, at least for the data that are explored in our study.

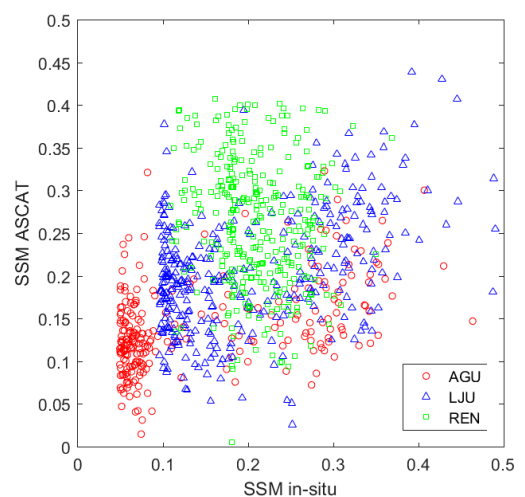

(a)

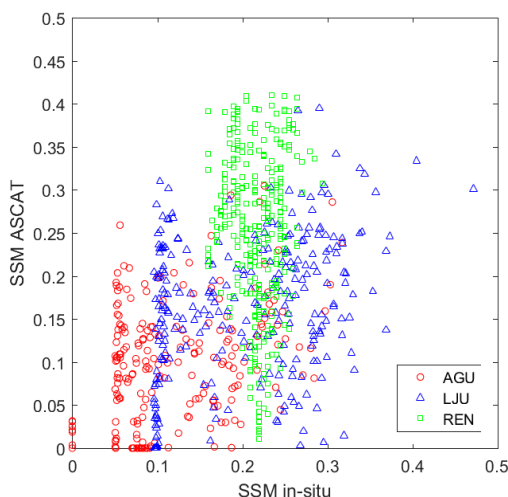

(b)

Figure 1. Scatter diagram of in situ and predicted SSM from ASCAT for the different land cover types in EUROPE, for year 2010 (a) and 2011 (b).

(i)

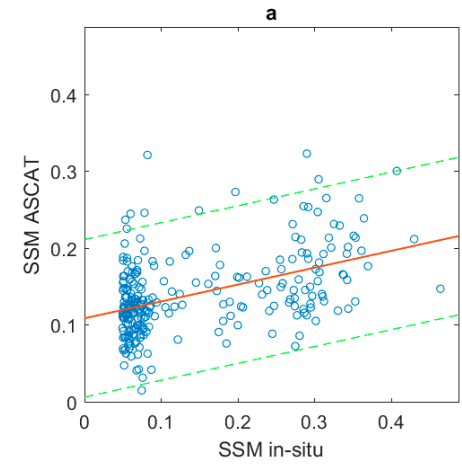

(ii)

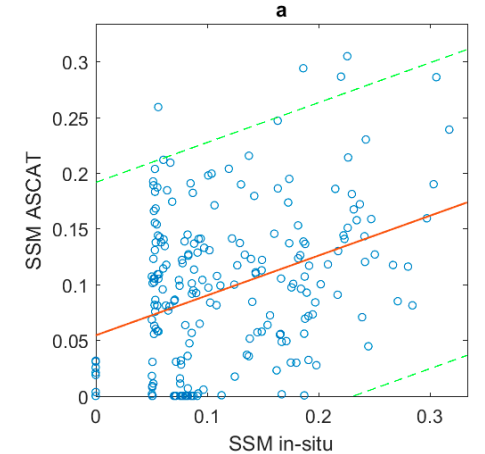

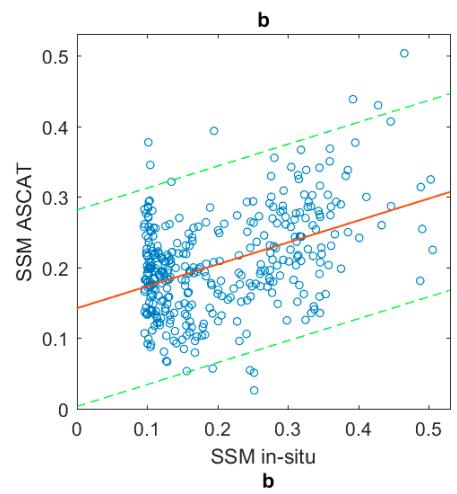

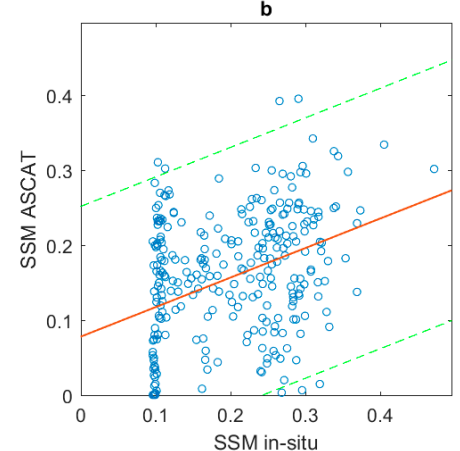

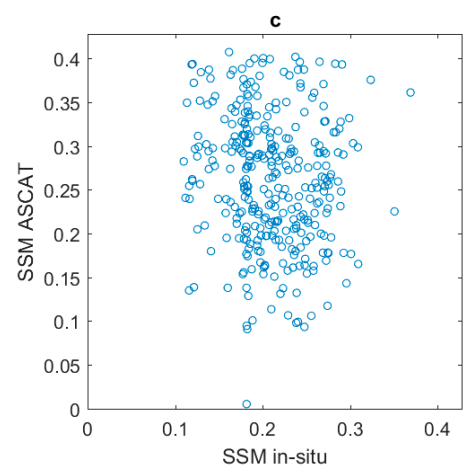

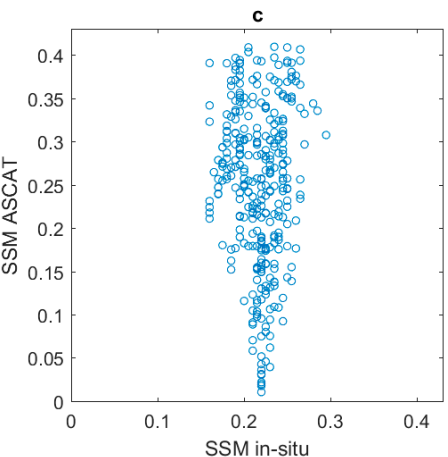

Figure 2. Scatter diagram of in situ and predicted SSM from ASCAT for the different land cover types in EUROPE in (i) 2010 and (ii) 2011. (a) ES_AGU, (b) ES_LJU, and (c) IT_REN. The green dashed lines represent the $95 \%$ confidence level.

\subsubsection{Seasonality}

Table 3 and Figures 3 and 4 show the temporal trends between in situ and ASCAT for different seasons during 2010 and 2011. In general, the plots in Figures 3 and 4 exhibit a good agreement in terms of seasonal trends. Overall, soil moisture values are highly responsive to seasonality, as indicated by marked fluctuations over the entire period and the rapid response to changes in weather (Figure 4). However, the ASCAT product overestimates the in situ observations of January to February and it underestimates the in situ observations from May to September, while it is consistent with the in situ trends from October to December over ES_AGU and ES_LJU. In contrast, it underestimates the in situ observations in January-February and from June to September over IT_REN (Figure 4). The same 
trends were observed in the year 2011 as well. Table 3 summarizes the seasonal comparisons for all the sites in 2010 and 2011. Figure 4 shows the agreement between predicted and observed SSM for the different seasons separately for 2010 and 2011. The RMSE is higher during 2011. The weakest correlations are evidenced in spring and winter of the year 2010.
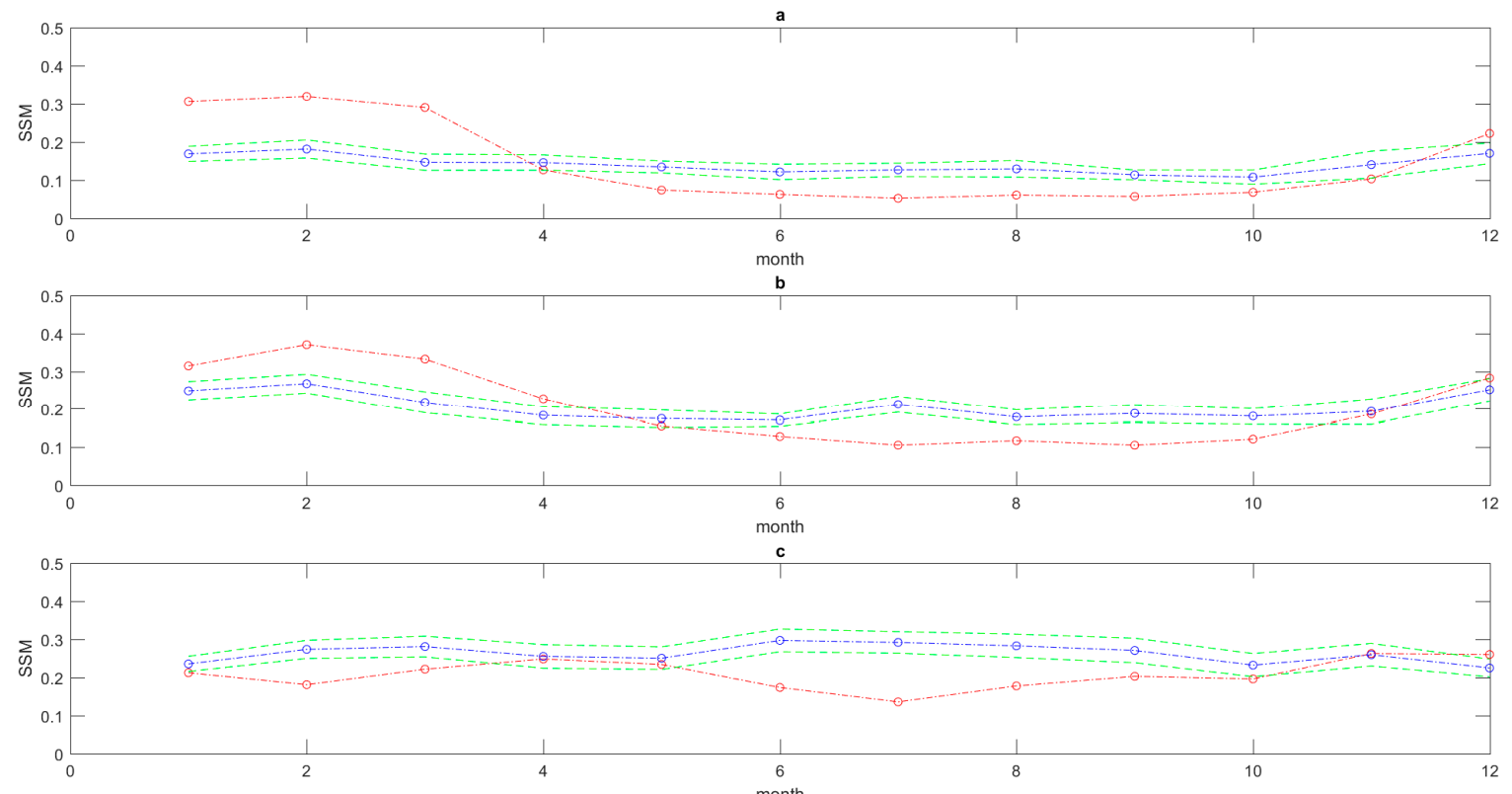

(i)
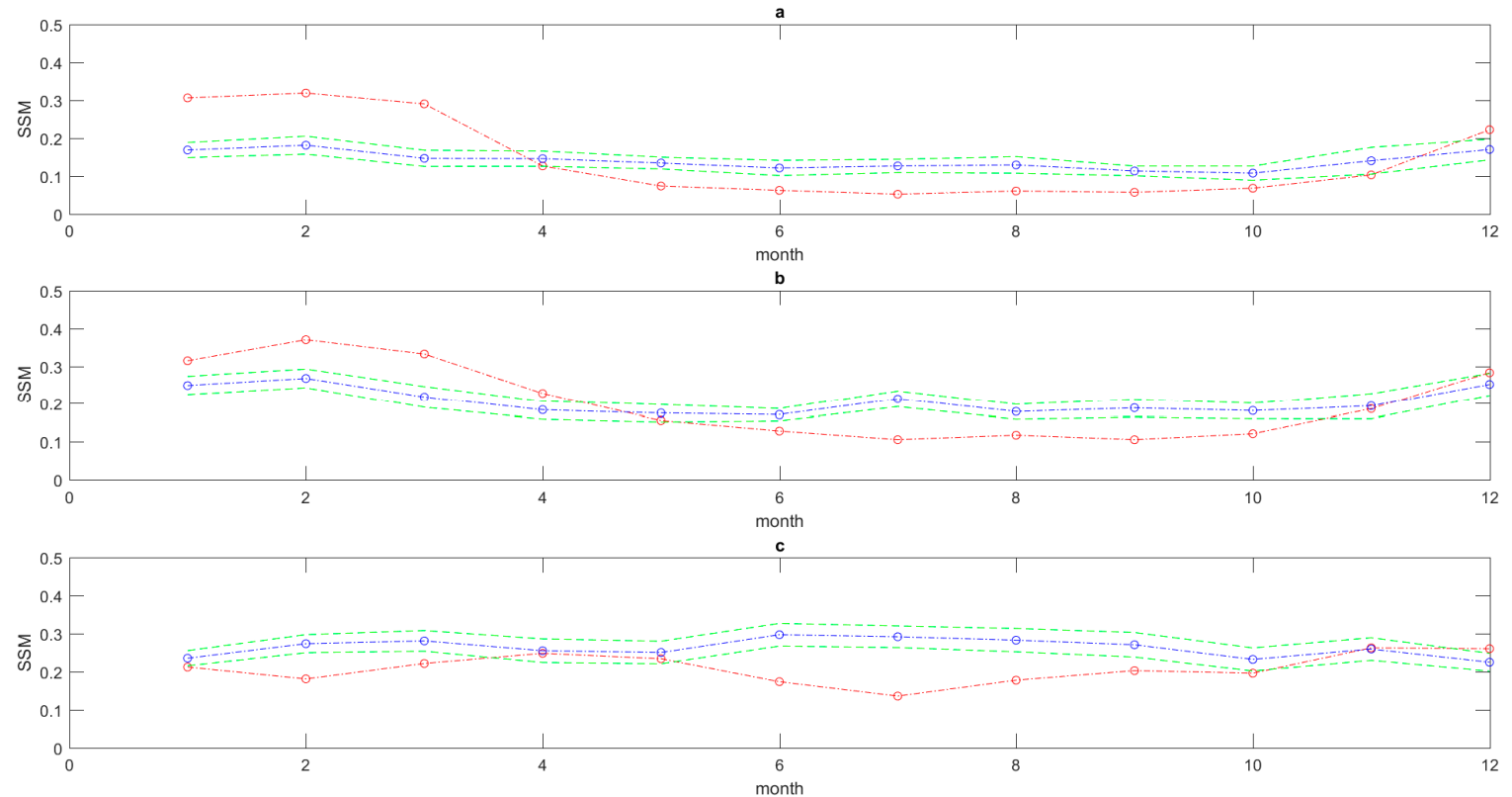

(ii)

Figure 3. Temporal dependence of monthly averages of in situ and predicted SSM from ASCAT $25 \mathrm{~km}$ for the different land cover types throughout in EUROPE. Results are shown for: (a) ES_AGU, (b) ES_LJU, and (c) IT_Ren. The blue curves represent the ASCAT SSM, the red curves represent the in situ SSM. (i) 2010 and (ii) 2011. The green dashed lines represent the 95\% confidence level. 

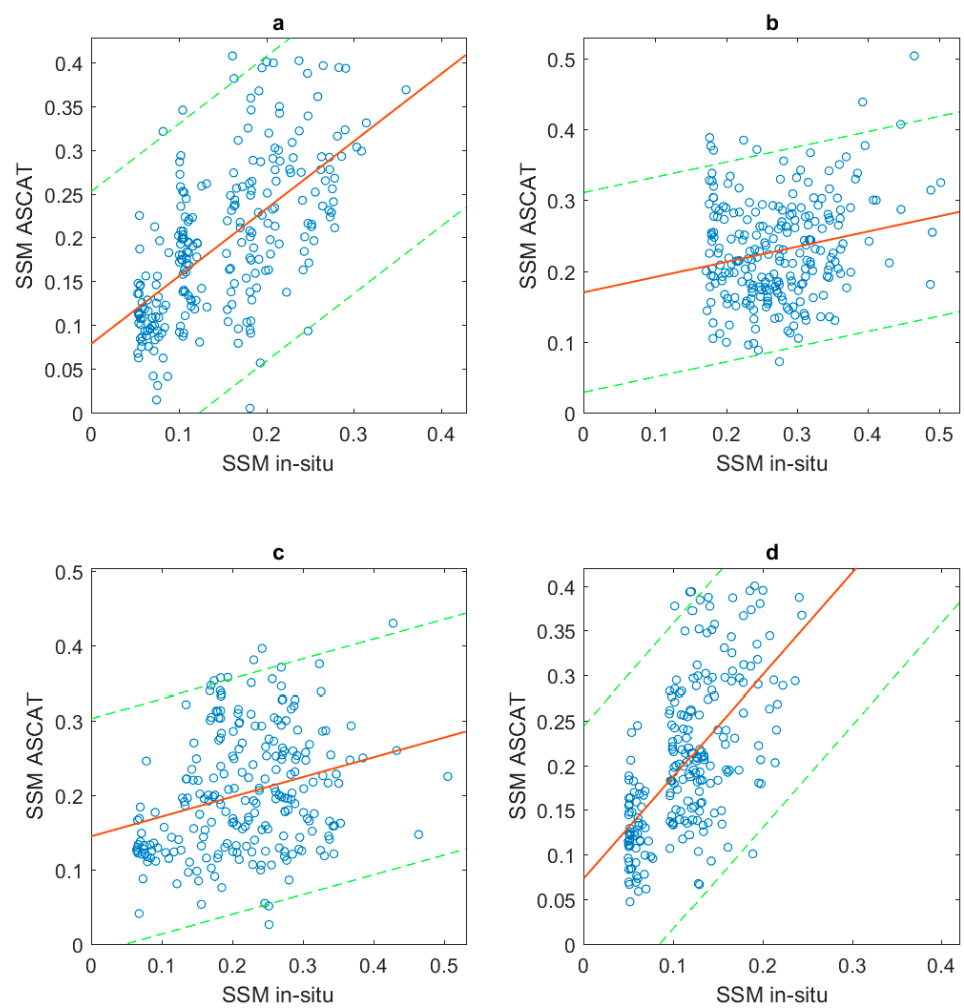

(i)
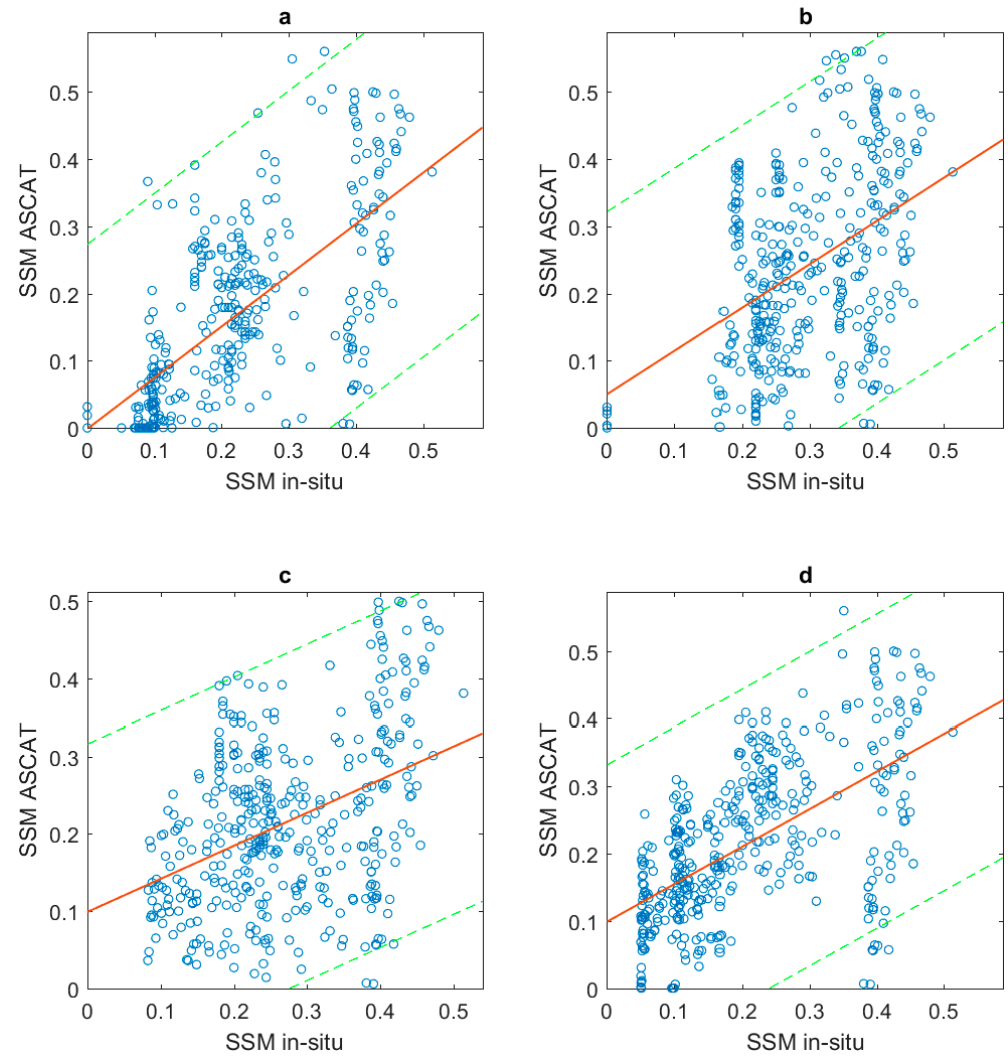

(ii)

Figure 4. (i) Scatter diagram of in situ and predicted SSM from ASCAT $25 \mathrm{Km}$ for the different seasons for all sites. For all sites in EUROPE (a) Autumn, (b) Winter, (c) Spring, and (d) Summer. Shown (i) 2010, (ii) 2011. The green dashed lines represent the 95\% confidence level. 
Table 3. Comparison per season between Satellite (ASCAT 25Km) and observed SSM at all validation sites in EUROPE for 2010 and 2011.

\begin{tabular}{ccccccccc}
\hline Measure & $\begin{array}{c}\text { Autumn } \\
\mathbf{2 0 1 0}\end{array}$ & $\begin{array}{c}\text { Winter } \\
\mathbf{2 0 1 0}\end{array}$ & $\begin{array}{c}\text { Spring } \\
\mathbf{2 0 1 0}\end{array}$ & $\begin{array}{c}\text { Summer } \\
\mathbf{2 0 1 0}\end{array}$ & $\begin{array}{c}\text { Autumn } \\
\mathbf{2 0 1 1}\end{array}$ & $\begin{array}{c}\text { Winter } \\
\mathbf{2 0 1 1}\end{array}$ & $\begin{array}{c}\text { Spring } \\
\mathbf{2 0 1 1}\end{array}$ & $\begin{array}{c}\text { Summer } \\
\mathbf{2 0 1 1}\end{array}$ \\
\hline ME & 0.044 & -0.045 & -0.016 & 0.089 & -0.055 & -0.056 & -0.055 & 0.008 \\
MAE & 0.065 & 0.081 & 0.081 & 0.093 & 0.093 & 0.115 & 0.101 & 0.085 \\
RMSE & 0.083 & 0.099 & 0.100 & 0.112 & 0.120 & 0.140 & 0.130 & 0.111 \\
R & 0.630 & 0.209 & 0.277 & 0.617 & 0.671 & 0.429 & 0.407 & 0.590 \\
Rs & 0.647 & 0.136 & 0.271 & 0.611 & 0.713 & 0.400 & 0.358 & 0.622 \\
Scatter & 0.070 & 0.089 & 0.099 & 0.068 & 0.107 & 0.129 & 0.117 & 0.111 \\
Slope & 0.771 & 0.215 & 0.266 & 1.139 & 0.762 & 0.644 & 0.429 & 0.558 \\
Intercept & 0.078 & 0.170 & 0.144 & 0.073 & -0.002 & 0.050 & 0.099 & 0.099 \\
N & 242 & 240 & 234 & 226 & 352 & 367 & 396 & 415 \\
\hline
\end{tabular}

\subsection{USA}

Statistical scores for evaluating the agreement between the ASCAT and the in situ reference soil moisture measurements from FLUXNET validated observational networks in the USA were used. The selected sites are mainly covered by grassland, open shrubland, and woody savanna. As shown in Table 4 and Figures 5 and 6, all of the days were determined and the main results are presented. Generally, as indicated from the statistical metrics computed for the case of comparison for all days, a relatively a good agreement between the two data sets was reported.

Table 4. Comparison between Satellite (ASCAT $25 \mathrm{Km}$ ) and observed SSM at validation sites in the United States of America (USA), including all datasets for 2010 and 2011.

\begin{tabular}{cccccccc}
\hline Measure & TON 2010 & TON 2011 & VAR 2010 & VAR 2011 & WHS 2010 & WHS 2011 & All Sites \\
\hline ME (Bias) & -0.048 & -0.011 & 0.028 & 0.041 & 0.030 & 0.018 & 0.008 \\
MAE & 0.092 & 0.113 & 0.067 & 0.082 & 0.042 & 0.034 & 0.074 \\
RMSE & 0.117 & 0.135 & 0.088 & 0.106 & 0.052 & 0.046 & 0.099 \\
R & 0.660 & 0.393 & 0.677 & 0.456 & 0.582 & 0.497 & 0.659 \\
Rs & 0.658 & 0.366 & 0.687 & 0.440 & 0.510 & 0.354 & 0.718 \\
Scatter & 0.107 & 0.135 & 0.083 & 0.098 & 0.043 & 0.042 & 0.099 \\
Slope & 0.523 & 0.294 & 0.871 & 0.619 & 0.877 & 0.778 & 0.598 \\
Intercept & 0.064 & 0.142 & 0.048 & 0.102 & 0.035 & 0.024 & 0.068 \\
N & 373 & 364 & 371 & 359 & 301 & 276 & 2044 \\
\hline
\end{tabular}

\subsubsection{Land Use and Land Cover Comparisons}

Table 4 and Figures 5 and 6 present the agreement between satellite-derived and in situ SSM for the different land cover types for the three USA sites. The product performed well in the year 2010 ( $\mathrm{R}$ is $58 \%, 66 \%$ and $68 \%$ ) on open shrubland, woody savanna, and grassland, respectively. It displayed minimum correlation in 2011 ( $\mathrm{R}$ is 39\%, 46\% and 50\%) on woody savanna, grassland, and open shrubland, respectively. Similarly to other continents, the correlation decreases in all sites in 2011. The RMSE for the woody savanna is consistently higher than other sites and it is the lowest for shrublands. The bias in the grasslands and the open shrubland was in all cases between 0.018 to $0.040 \mathrm{~m}^{3} \mathrm{~m}^{-3}$; however for the woody savanna the bias showed an underestimation with dry bias of $\left(-0.048,-0.011 \mathrm{~m}^{3} \mathrm{~m}^{-3}\right)$ in 2010 and 2011, respectively. 


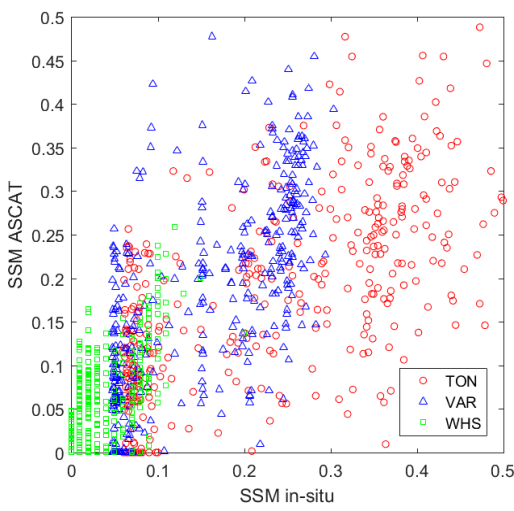

(a)

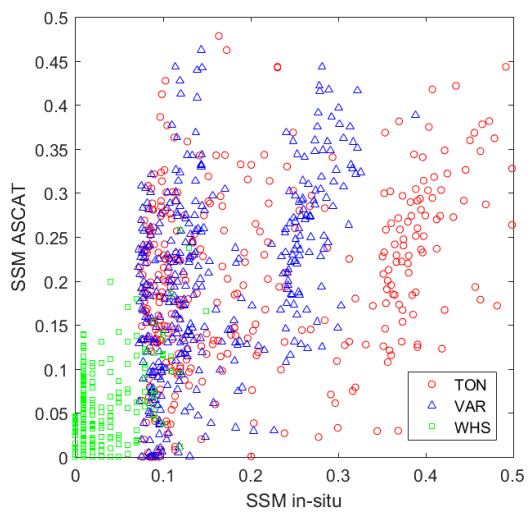

(b)

Figure 5. Scatter diagram of in situ and predicted SSM from ASCAT for all different land cover types in USA sites include US_TON, US_VAR and US_WHS (a) 2010 and (b) 2011.
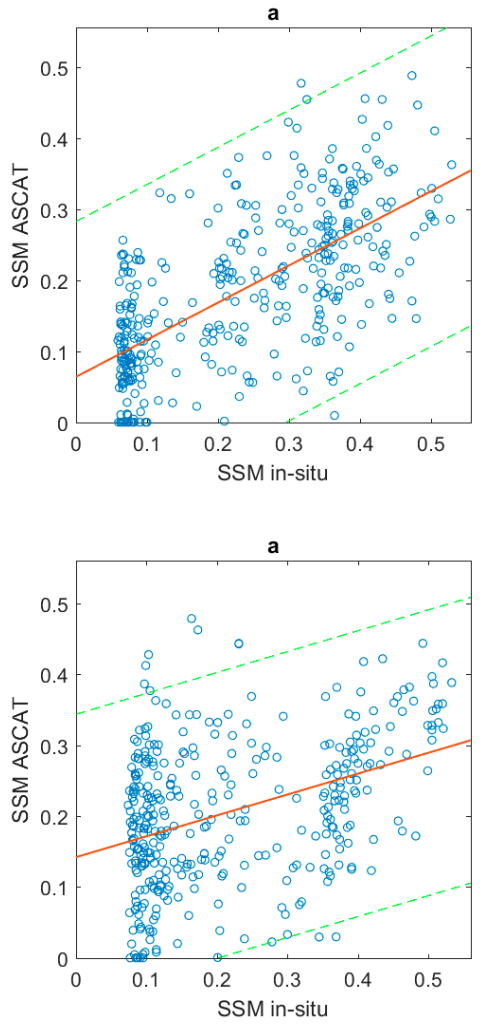

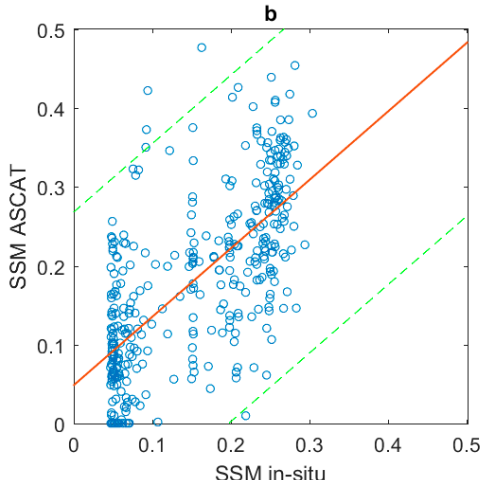

(i)

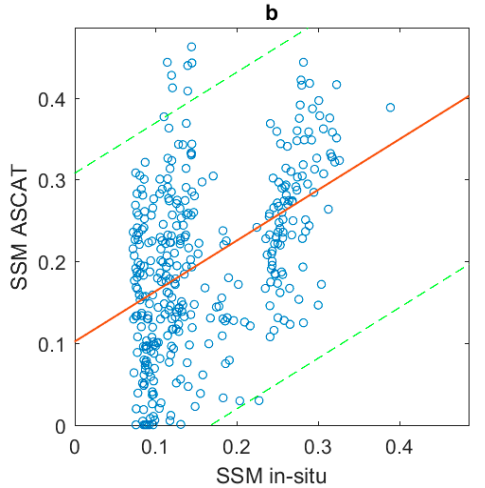

(ii)
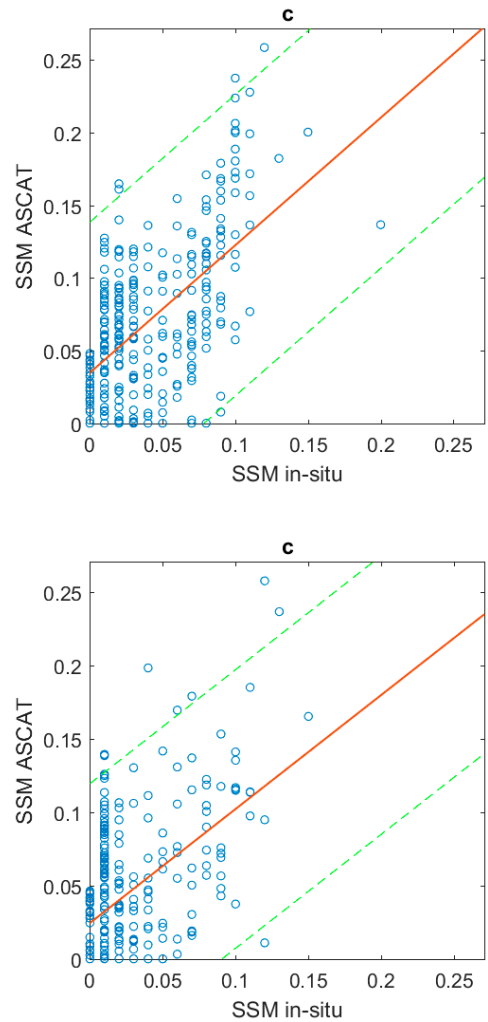

Figure 6. Scatter diagram of in situ and predicted SSM from ASCAT $25 \mathrm{Km}$ for the different land cover types in (i) 2010 and (ii) 2011. The USA sites include (a) US_TON, (b) US_VAR, and (c) US_WHS. The green dashed lines represent the $95 \%$ confidence level.

\subsubsection{Seasonality}

A further analysis was conducted while examining the agreement between the compared data set by seasons during 2010 and 2011 are shown in time series on Figure 7 for all three sites. In general, comparisons between the in situ and ASCAT products time series exhibit high temporal variability with seasons and they depict a strong seasonal cycle. In general, soil moisture values are highly responsive with the seasonality indicated by marked fluctuations over the entire period with rapid and sharp responses, even changes in weather, as shown in Figure 7. Except for the WHS (woody 
savanna) from February to April, the pattern showed an overestimation to the in situ measurements during these months in both years 2010-2011.

In Table 5 and Figure 7, representing the seasonality of all the stations, the correlation values are high (all between $60 \%$ to $77 \%$ ), except for summer the correlation is low. The ASCAT products evaluated soil moisture in short term seasonal variability better in winter and autumn than in spring and summer.
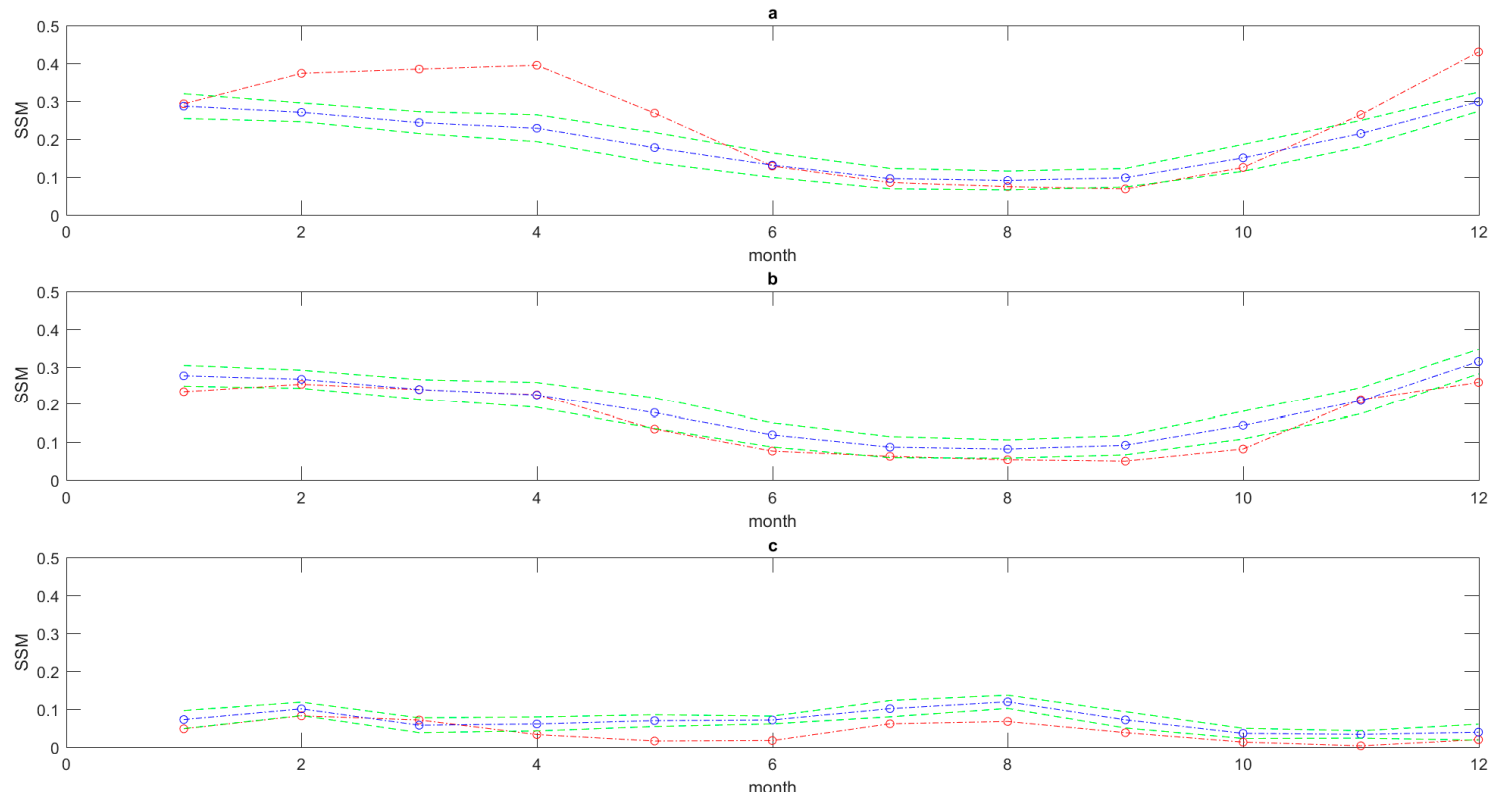

(i)
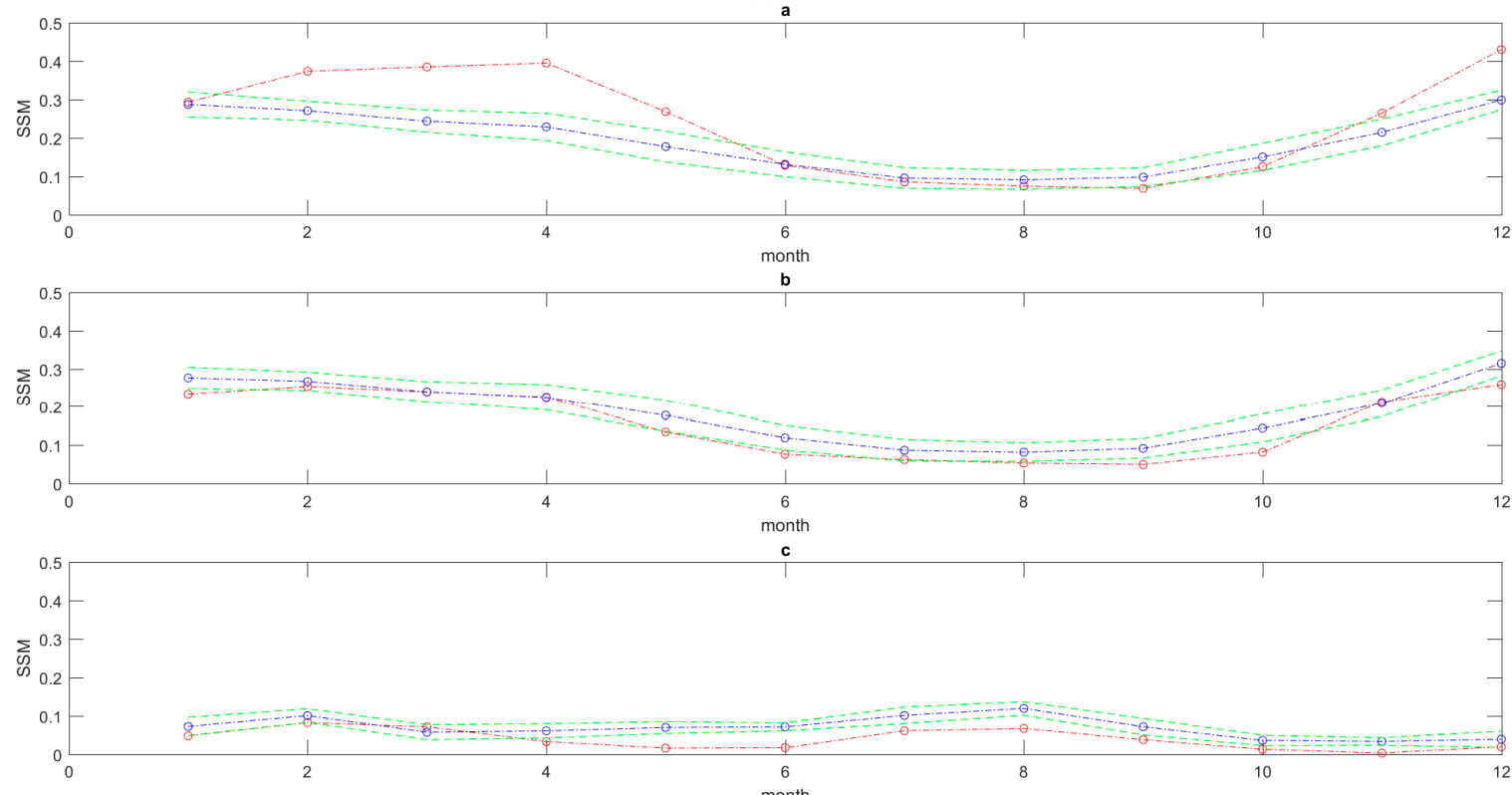

(ii)

Figure 7. Temporal dependence of monthly averages of in situ and predicted SSM from ASCAT 25Km for the different land cover types of USA throughout (i) 2010 and (ii) 2011. Results are shown for: (a) US_TON, (b) US_VAR, and (c) US_WHS. Blue is the ASCAT SSM and red is the in situ SSM. The green dashed lines represent the $95 \%$ confidence level. 

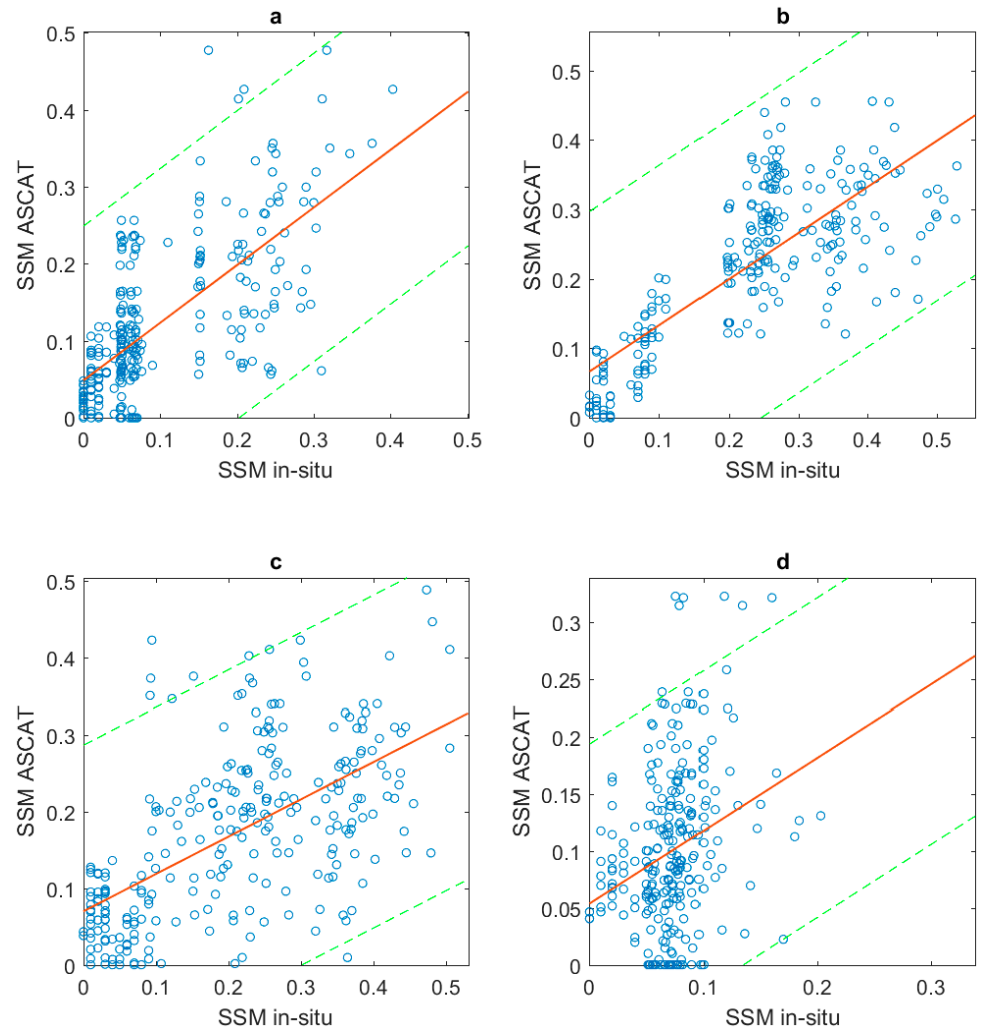

(i)
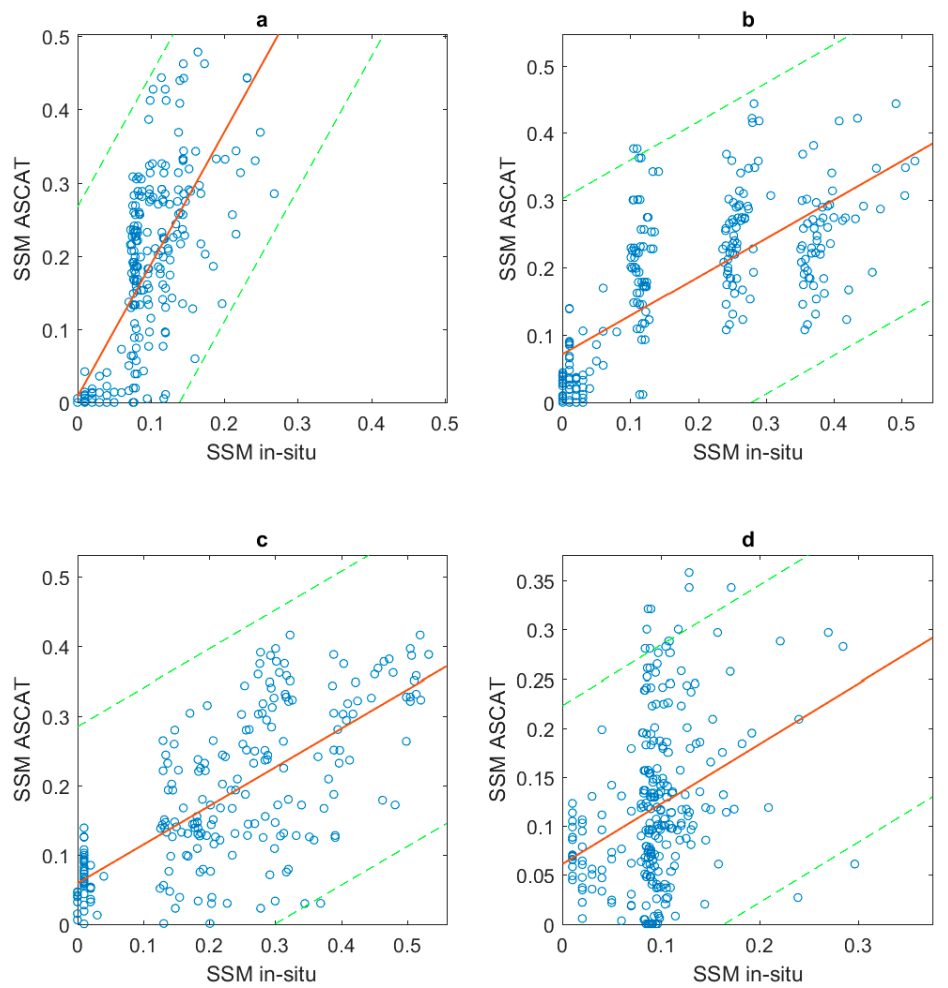

(ii)

Figure 8. Scatter diagram of in situ and predicted SSM from ASCAT $25 \mathrm{Km}$ for the different seasons for all sites in EUROPE together shown here for year (i) 2010 and (ii) 2011. For all sites in USA (a) Autumn, (b) Winter, (c) Spring, and (d) Summer. The green dashed lines represent the 95\% confidence level. 
Table 5. Comparison between Satellite (ASCAT 25Km) and observed SSM at validation sites in USA, including all of the datasets for 2010 and 2011.

\begin{tabular}{ccccccccc}
\hline Measure & $\begin{array}{c}\text { Autumn } \\
\mathbf{2 0 1 0}\end{array}$ & $\begin{array}{c}\text { Winter } \\
\mathbf{2 0 1 0}\end{array}$ & $\begin{array}{c}\text { Spring } \\
\mathbf{2 0 1 0}\end{array}$ & $\begin{array}{c}\text { Summer } \\
\mathbf{2 0 1 0}\end{array}$ & $\begin{array}{c}\text { Autumn } \\
\mathbf{2 0 1 1}\end{array}$ & $\begin{array}{c}\text { Winter } \\
\mathbf{2 0 1 1}\end{array}$ & $\begin{array}{c}\text { Spring } \\
\mathbf{2 0 1 1}\end{array}$ & $\begin{array}{c}\text { Summer } \\
\mathbf{2 0 1 1}\end{array}$ \\
\hline ME & 0.023 & -0.011 & -0.036 & 0.028 & 0.077 & -0.007 & -0.040 & 0.025 \\
MAE & 0.061 & 0.066 & 0.090 & 0.058 & 0.093 & 0.077 & 0.087 & 0.064 \\
RMSE & 0.081 & 0.088 & 0.118 & 0.074 & 0.123 & 0.103 & 0.111 & 0.083 \\
R & 0.690 & 0.773 & 0.603 & 0.279 & 0.757 & 0.713 & 0.712 & 0.333 \\
Rs & 0.686 & 0.740 & 0.626 & 0.303 & 0.774 & 0.723 & 0.694 & 0.320 \\
Scatter & 0.077 & 0.087 & 0.112 & 0.069 & 0.097 & 0.103 & 0.103 & 0.079 \\
Slope & 0.749 & 0.664 & 0.487 & 0.640 & 1.807 & 0.572 & 0.558 & 0.612 \\
Intercept & 0.048 & 0.067 & 0.070 & 0.054 & 0.008 & 0.072 & 0.059 & 0.061 \\
N & 271 & 241 & 270 & 263 & 261 & 255 & 226 & 257 \\
\hline
\end{tabular}

\subsection{Australia}

The ASCAT product performed very satisfactory in Australia with relatively higher Pearson and Spearman coefficients (see Table 6 and Figures 9 and 10). In general, ASCAT showed an overestimation, as shown in Figure 11. The bias is always positive and of significant value. The bias over the different vegetation cover types, the values generally range between $\left(0.012\right.$ to $\left.0.66 \mathrm{~m}^{3} \mathrm{~m}^{-3}\right)$, but the higher bias of $0.083 \mathrm{~m}^{3} \mathrm{~m}^{-3}$ was indicated over HS (woody savanna). Overall, the bias that is shown in Australia is the higher bias of the other continents. RMSE is generally between 0.088 to $0.12 \mathrm{~m}^{3} \mathrm{~m}^{-3}$ in Australia.

Table 6. Comparison between Satellite (ASCAT $25 \mathrm{Km}$ ) and observed SSM at validation sites in AUSTRALIA based on land cover type for 2010 and 2011.

\begin{tabular}{cccccccc}
\hline Measure & DPA 2010 & DPA 2011 & HS 2010 & HS 2011 & STP 2010 & STP 2011 & All Sites \\
\hline ME (Bias) & 0.052 & 0.066 & 0.083 & 0.048 & 0.012 & 0.061 & 0.053 \\
MAE & 0.073 & 0.072 & 0.093 & 0.092 & 0.059 & 0.080 & 0.078 \\
RMSE & 0.094 & 0.098 & 0.111 & 0.115 & 0.088 & 0.107 & 0.103 \\
R & 0.665 & 0.904 & 0.697 & 0.739 & 0.693 & 0.342 & 0.722 \\
Rs & 0.625 & 0.905 & 0.734 & 0.790 & 0.733 & 0.367 & 0.743 \\
Scatter & 0.079 & 0.073 & 0.075 & 0.104 & 0.087 & 0.087 & 0.088 \\
Slope & 1.570 & 1.976 & 1.392 & 1.920 & 1.684 & 0.582 & 1.328 \\
Intercept & -0.009 & -0.034 & 0.039 & -0.064 & -0.066 & 0.161 & 0.011 \\
N & 287 & 275 & 288 & 297 & 294 & 237 & 1678 \\
\hline
\end{tabular}

\subsubsection{Land Use and Land Cover Comparisons}

Table 6 summarizes the comparison of the predicted ASCAT product and the observed soil moisture at the three experimental sites of varying land use and land cover in 2010 and 2011. The grassland (DPA) and woody savanna (HS) exhibited the closer agreement than STP (also grasslands). Strong bias and slope is displayed in all sites. Figure 11 presents the histogram of SSM in situ and ASCAT for all sites and the mean SSM (in situ and ASCAT). Figure 11, in combination with Figure 9, make evident that ASCAT measurements generally overestimate the soil moisture. Conclusions that are based on land type cannot be drawn without further investigation, except to note that RMSE for woody savannas seems to be slightly higher than for grasslands. 


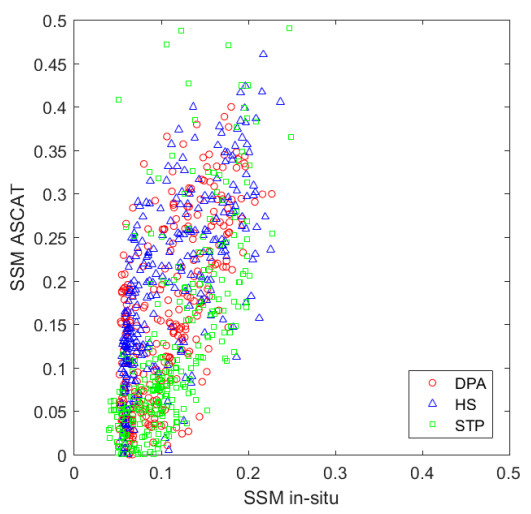

(a)

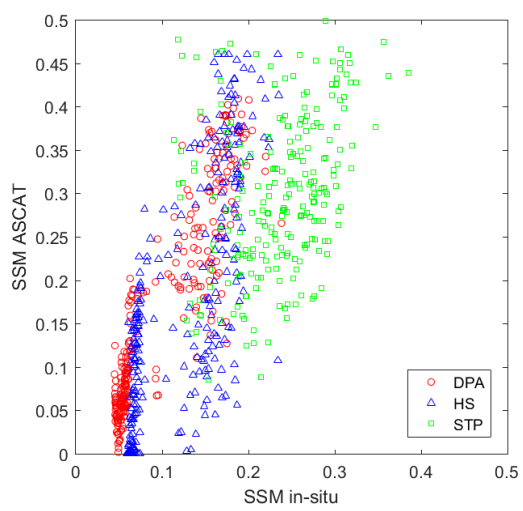

(b)

Figure 9. Scatter diagram of in situ and predicted SM from ASCAT for all different land cover types in (a) 2010 and (b) 2011. The AUSTRALIA sites include AU_DPA, AU_HS, and AU_STP.
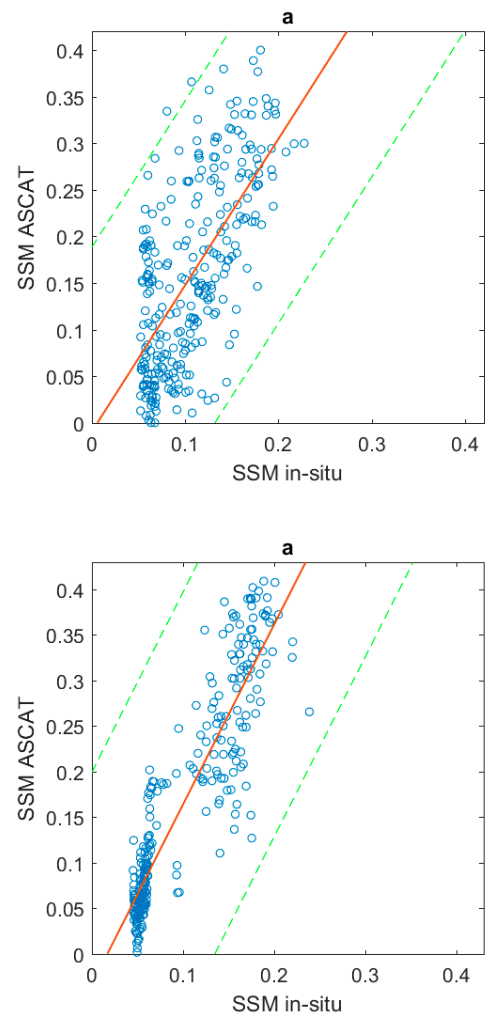

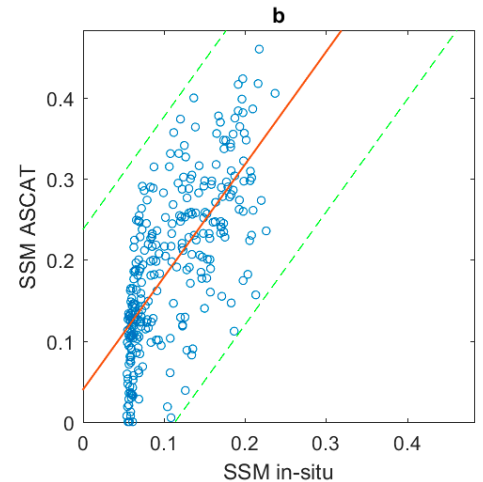

(i)

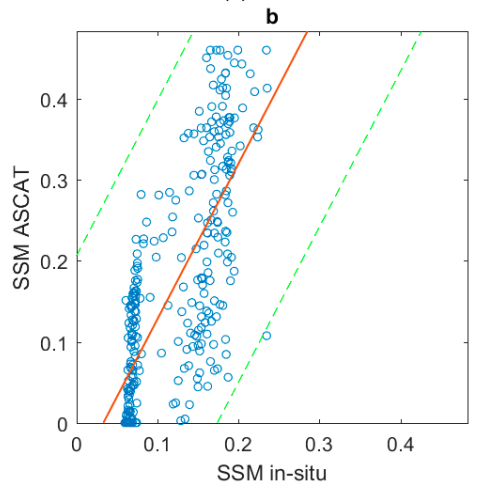

(ii)
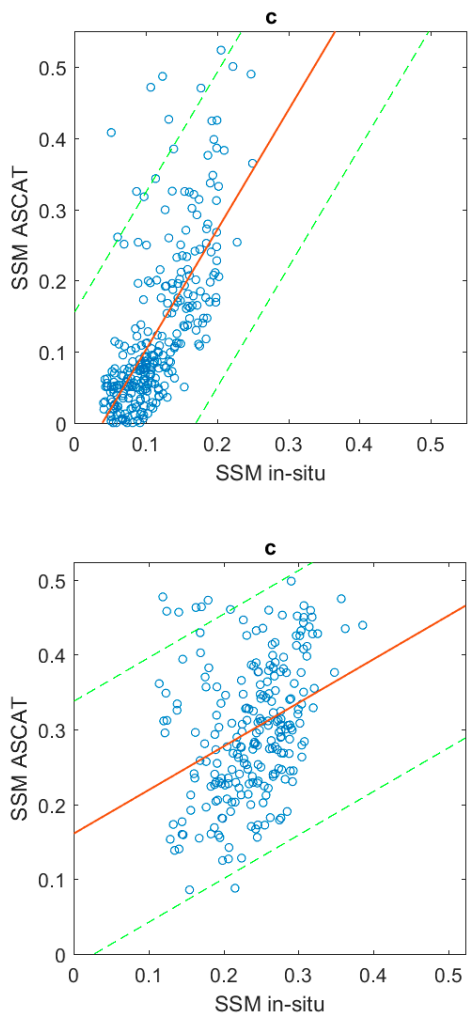

Figure 10. (i) Scatter diagram of in situ and predicted SM from ASCAT $25 \mathrm{Km}$ for the different land cover types in 2010 (ii) in 2011. The AUSTRALIA sites include (a) AU_DPA, (b) AU_HS, and (c) AU_STP. The green dashed lines represent the $95 \%$ confidence level. 


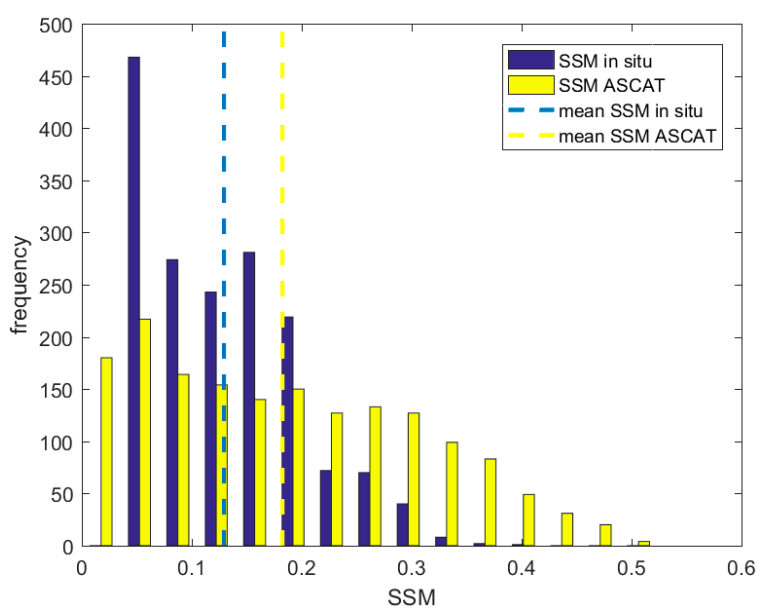

Figure 11. Histogram of Soil Moisture $\left(\mathrm{m}^{3} \mathrm{~m}^{-3}\right)$ for all Australian sites combined for both years for in situ measurements (blue) and ASCAT measurements (yellow), mean SSM for in situ and ASCAT are presented.

\subsubsection{Seasonality}

Figure 12 shows the temporal trends between in situ and predicted ASCAT predicted soil moisture for different seasons during 2010 and 2011 for the selected sites. Overall, the predicted SSM for ASCAT product well reflects the actual soil moisture from May to October and satisfactorily captures the trend of the changes in SSM, even though they provide overestimations from December to March. In addition, soil moisture values fluctuations of soil moisture over the entire period are marked with rapid and sharp responses over the AU_STP, which can be seen in Figure 12.

Table 7 summarizes the comparisons between the seasons and Figure 13 shows the agreement between the predicted and observed soil moisture for the different seasons separately for 2010 and 2011. In general, the data display the highest bias during summer and autumn, especially in 2011. RMSE has high values in autumn and summer (between 0.1 to $0.16 \mathrm{~m}^{3} \mathrm{~m}^{-3}$ ). However, winter and spring showed the highest Pearson's coefficient in both years, respectively. Spearman's rank correlation coefficient, which investigates the correlation between the ranks of each value, shows high divergence from the Pearson's coefficient for winter 2010. The latter suggests that the two variables (ASCAT SSM and in situ SSM) can be considered to have only a moderately satisfactory monotonic relation.

Table 7. Comparison per season between Satellite (ASCAT 25Km) and observed SSM at all validation sites in AUSTRALIA for 2010, 2011, and both years.

\begin{tabular}{ccccccccc}
\hline Measure & $\begin{array}{c}\text { Autumn } \\
\mathbf{2 0 1 0}\end{array}$ & $\begin{array}{c}\text { Winter } \\
\mathbf{2 0 1 0}\end{array}$ & $\begin{array}{c}\text { Spring } \\
\mathbf{2 0 1 0}\end{array}$ & $\begin{array}{c}\text { Summer } \\
\mathbf{2 0 1 0}\end{array}$ & $\begin{array}{c}\text { Autumn } \\
\mathbf{2 0 1 1}\end{array}$ & $\begin{array}{c}\text { Winter } \\
\mathbf{2 0 1 1}\end{array}$ & $\begin{array}{c}\text { Spring } \\
\mathbf{2 0 1 1}\end{array}$ & $\begin{array}{c}\text { Summer } \\
\mathbf{2 0 1 1}\end{array}$ \\
\hline ME & 0.070 & 0.022 & 0.037 & 0.092 & 0.112 & 0.061 & 0.034 & 0.129 \\
MAE & 0.086 & 0.058 & 0.064 & 0.108 & 0.125 & 0.074 & 0.077 & 0.136 \\
RMSE & 0.109 & 0.076 & 0.086 & 0.131 & 0.146 & 0.096 & 0.102 & 0.160 \\
R & 0.536 & 0.921 & 0.755 & 0.462 & 0.530 & 0.798 & 0.459 & 0.342 \\
Rs & 0.521 & 0.557 & 0.647 & 0.448 & 0.504 & 0.415 & 0.319 & 0.349 \\
Scatter & 0.084 & 0.073 & 0.077 & 0.094 & 0.094 & 0.074 & 0.097 & 0.095 \\
Slope & 0.929 & 1.532 & 1.182 & 0.979 & 0.779 & 1.027 & 0.777 & 0.964 \\
Intercept & 0.080 & -0.039 & 0.013 & 0.095 & 0.149 & 0.058 & 0.056 & 0.135 \\
N & 288 & 295 & 270 & 274 & 284 & 314 & 235 & 234 \\
\hline
\end{tabular}



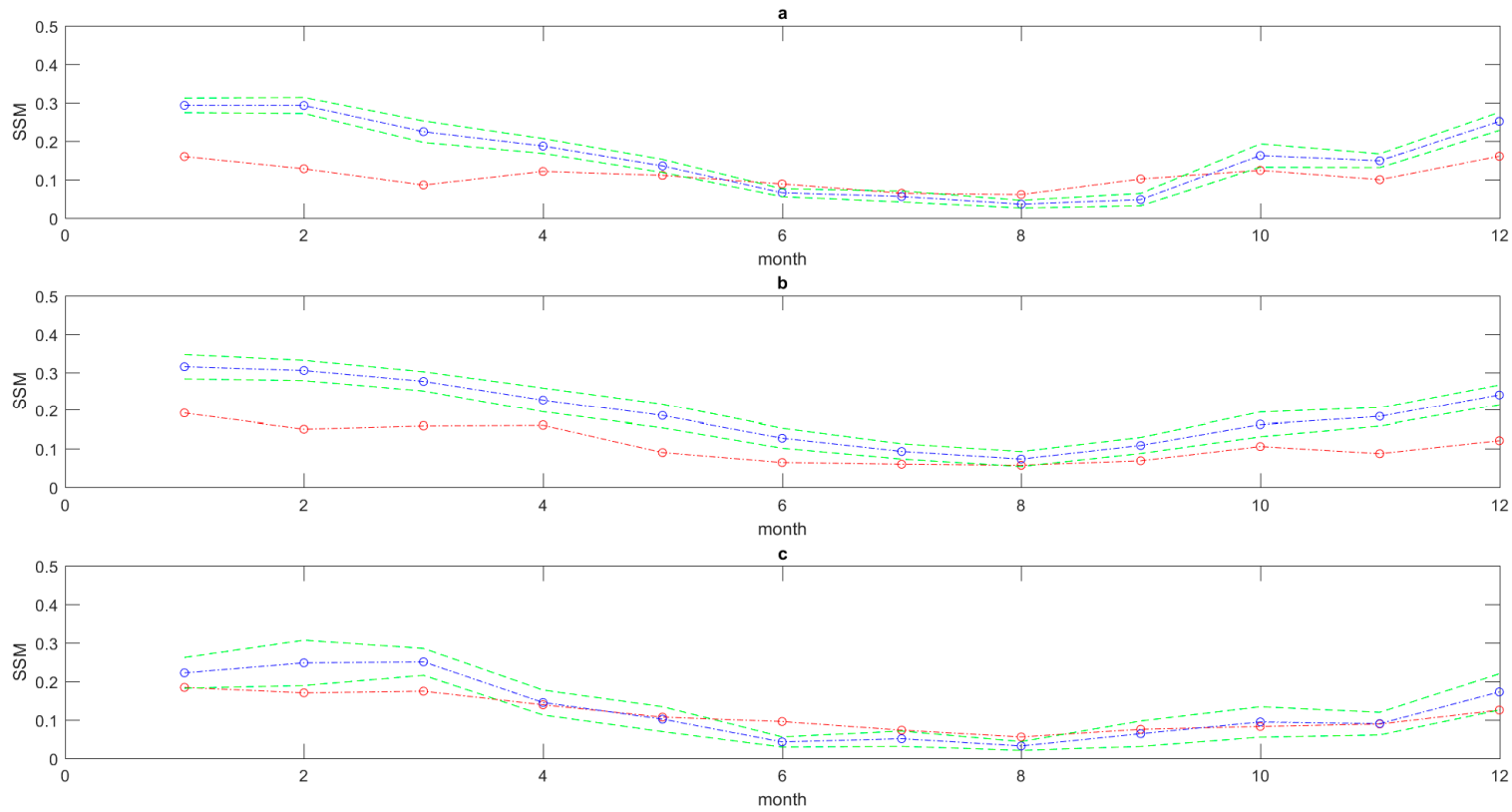

(i)
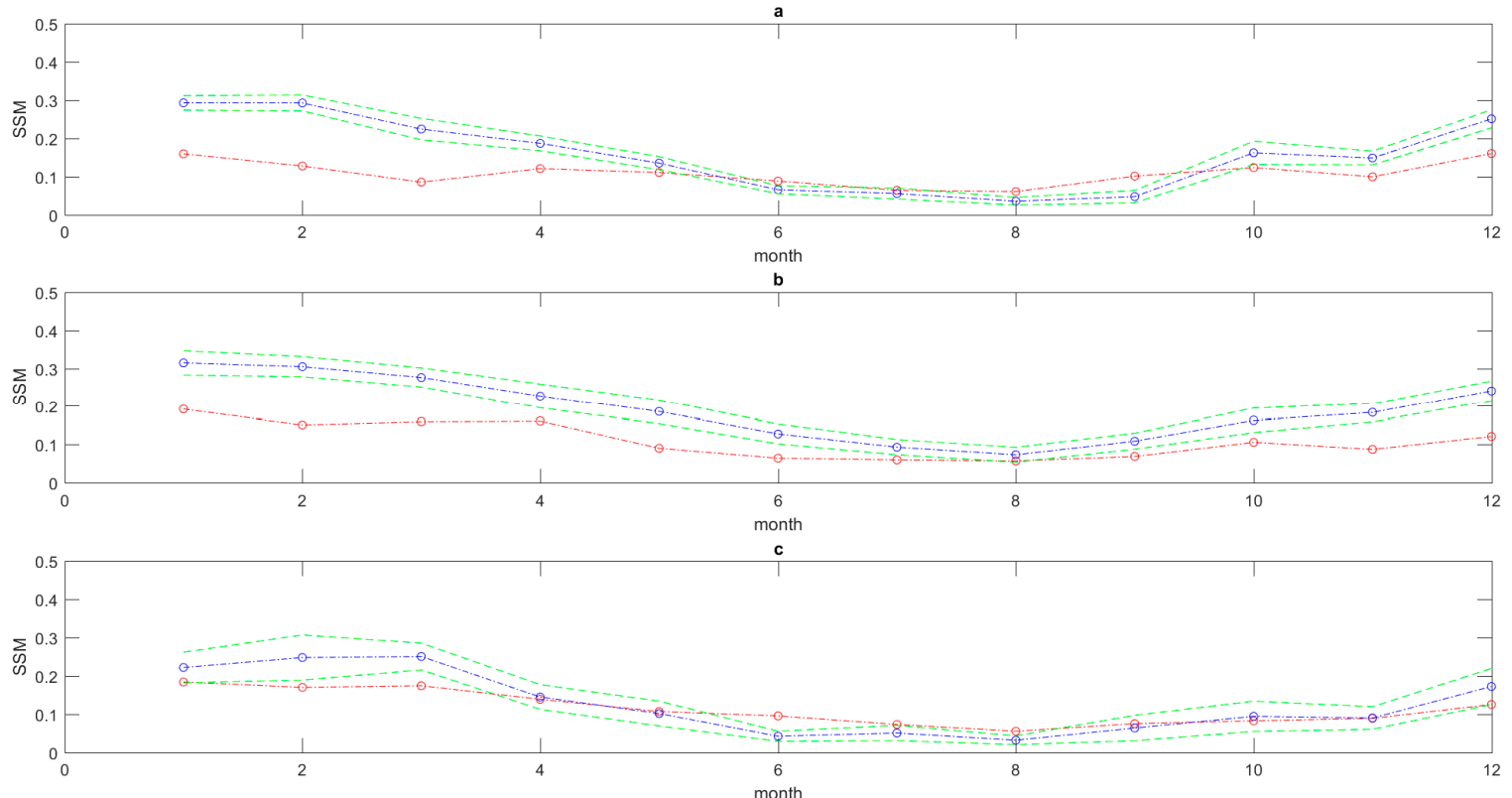

(ii)

Figure 12. Temporal dependence of monthly averages of in situ and predicted SSM from ASCAT 25Km for the different land cover types in AUSTRALIA. Results are shown for: (a) AU_DPA, (b) AU_HS, and (c) AU_STP. Blue is the ASCAT SSM and red is the in situ SSM (i) 2010 and (ii) 2011. The green dashed lines represent the $95 \%$ confidence level. 

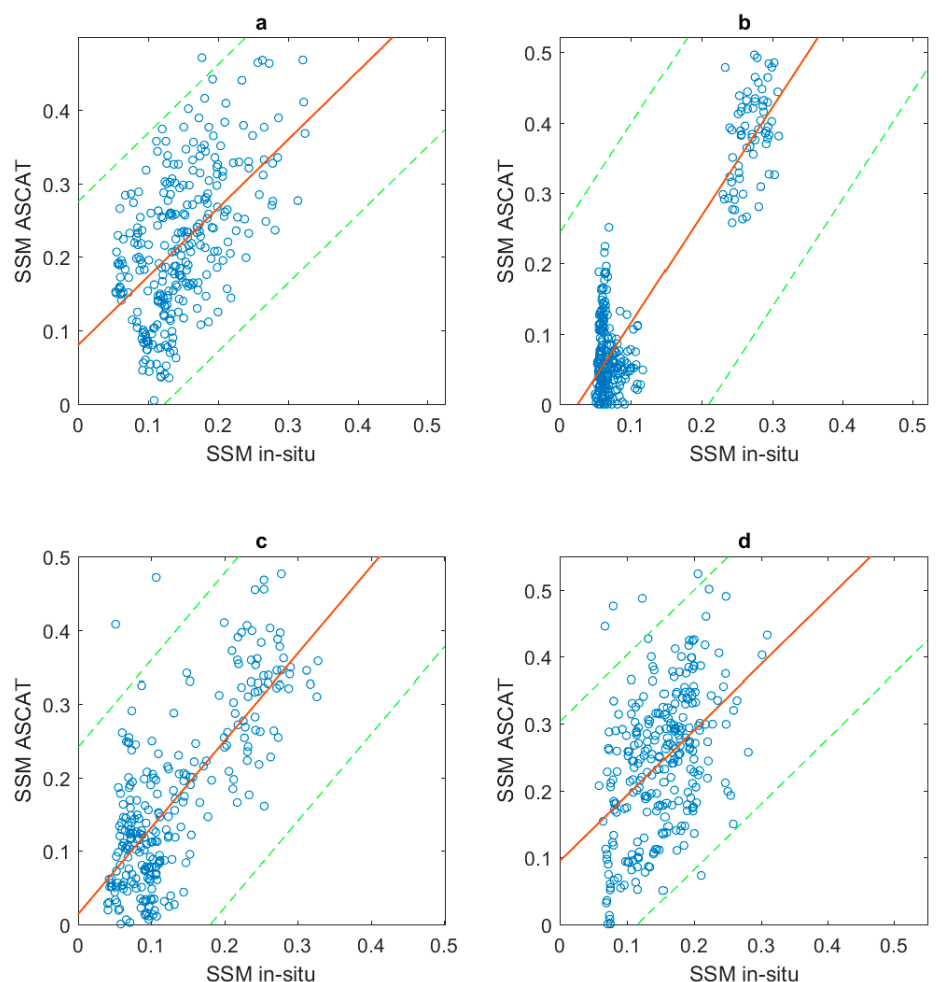

(i)
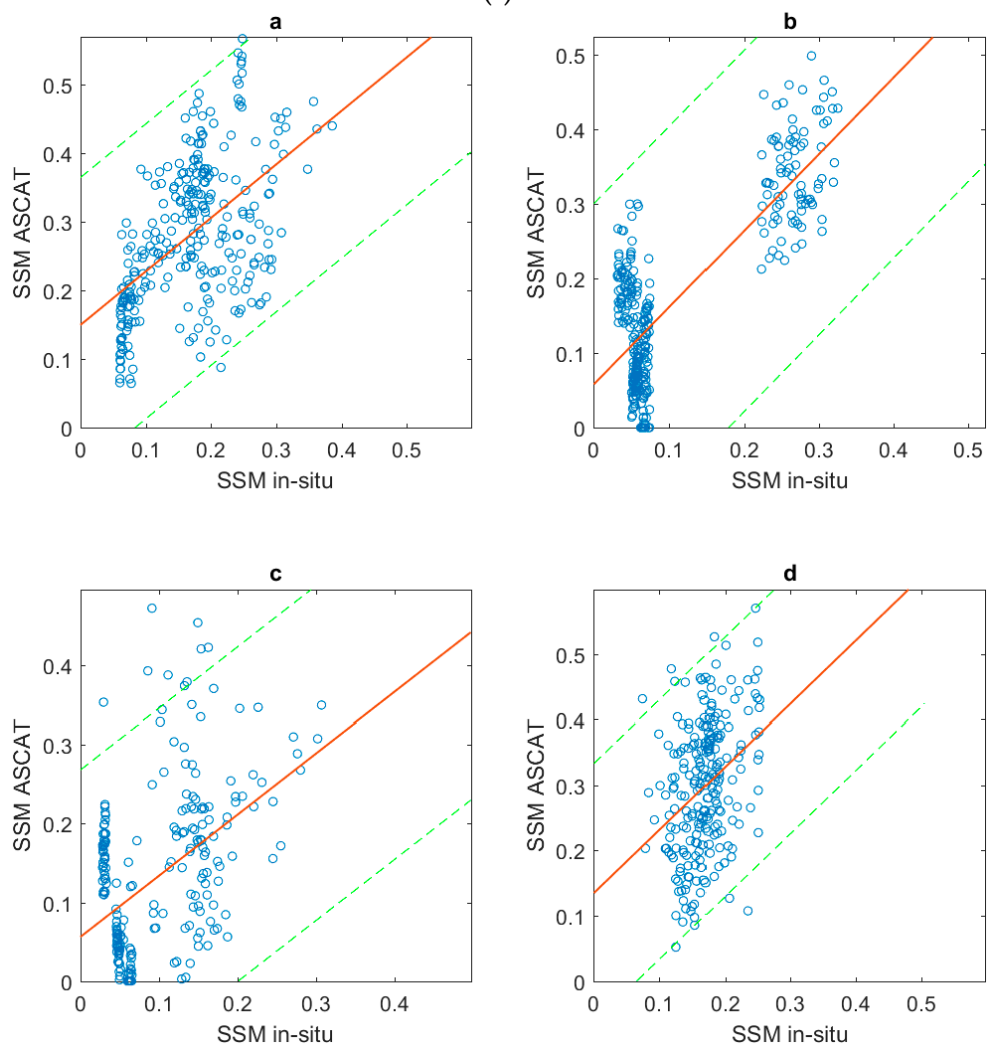

(ii)

Figure 13. Scatter diagram of in situ and predicted SM from ASCAT 25Km for the different seasons for all sites together shown here for year (i) 2010 and (ii) 2011. For all sites in AUSTRALIA (a) Autumn, (b) Winter, (c) Spring, and (d) Summer. The green dashed lines represent the 95\% confidence level. 


\section{Discussion}

This study provided the results of a systematic and robust evaluation of the ASCAT soil moisture operational product at a range of selected ecosystems in Europe, USA, and Australia for 2010 and 2011. The accuracy of the ASCAT soil moisture product was analyzed to evaluate the effect of varying land use land cover and seasonality. Overall, ASCAT was able to adequately reflect the trends, seasonal variation of ground soil moisture recorded, with high $\mathrm{R}$ and relatively low bias and good RMSE generally. Additionally, the Spearman's rank correlation coefficient, which investigates the correlation between the ranks of each value, generally showed suitable divergence from the Pearson's coefficient, meaning that the two variables (ASCAT and in situ SSM) can be considered to have only a satisfactory monotonic relation. This result is coincident with previous studies that compared the performance of ASCAT SSM product based on observation networks in Europe [45-47]. As shown in Tables 1-7, the metrics generally showed very good accuracies over all the selected sites. Based on the different land cover types, ASCAT has shown reasonable R values and low RMSE over grasslands and shrublands for both years. The product performed moderately on the woody savannas and poorly on needleleaf forest where the RMSE was relatively very high.

Overall, possible explanations for the errors can be as follows: (1) Topographic complexity, high vegetation density (e.g., taller and/or denser), frozen soils, snow cover, and volume scattering in dry soils are very critical for soil moisture operational products retrieval accuracy [48]. With regards to vegetation, vegetation structure and water content, if not accounted for properly, could strongly affect the quality of soil moisture retrievals. Recent studies suggested that the vegetation water content variation during daytime may have a stronger impact on backscatter than previously thought $[49,50]$. Previous works (e.g., [51,52]) have stated that the vegetation is more transparent during the daytime when the temperature is high. The latter is resulting in less effect of vegetation on emission attenuation from soil given the fact that the TU Wien soil moisture retrieval model currently does not account for the diurnal vegetation effects. Therefore, research is needed to quantify these effects and to correct them as far as possible [48,53]. Further research also needs to be focused on impact of growing and non-growing season impact on soil moisture assessment and accuracy. Other researchers indicated that, because of crops in the growing season, high attenuation takes place, which impacts soil moisture retrievals, and hence less agreement with the in situ measurements is displayed [54]. (2) The sensing depth of ASCAT is very shallow. In our study, the surface ground measurements used for the evaluation are at $5 \mathrm{~cm}$. The sampling depth of the effective soil moisture at C-band is $0-3 \mathrm{~cm}$ [35]. This could also be achieved when the TU Wien soil moisture retrieval model account for the nighttime since near-surface soil moisture profile could be more uniform and it could be captured at the $(\sim 0.5-2)$ layer sampled by ASCAT. (3) Different spatial observation scale. The differences in spatial resolution can introduce some deviation. Since the exact scale of the satellite observation could not be represented by ground observation, the average point-based measurement is used as a "reference". However, it is also argued in many studies that it is difficult to characterize the spatial soil moisture patterns by using in situ measurement. It can be only reproduce the temporal dynamic of soil moisture but not the absolute value [24,31]. This can be achieved by upscaling the coarse scale of the point soil moisture measurement using recently proposed methods for this purpose (e.g., [55,56]). Sometimes, if the in situ sensors are not dense enough, it causes mismatch in scales and hence poor accuracy in comparison. The solution to this is to use downscaled or spatially disaggregated data for a better comparison with the in situ datasets [57]. (4) Errors that are caused by measurements accuracy of the sensors. It has been found that the land surface factors, such as topography, season, and land cover types (particularly at the presence of forests) have been pointed out as elements that affect the product accuracy and consistency, in addition to that they affect the quality of the product that can be expected by the final user $[44,46,58]$.

The topographic complexity is highlighted as the main reason that leads to different performance of ASCAT products over the different land use land cover regions. When the results are stratified by land cover type, clear inter-site variability in retrieval accuracy becomes evident. As shown in 
Tables 1-7, the open shrubland sites and the grassland exhibit very low RMSE and perform very well in term of the correlation coefficient. On the other hand, woody savanna and Evergreen needleleaf Forest (IT_REN) have the highest RMSE among the land cover types that are studied herein. The absence of correlation can be mainly described by the lack of spatial sampling between predicted and observed comparison [59]. The weakest correlations are seen in spring and winter in Europe. This can be relatively attributed to the possibility of lesser fractional vegetation cover than other seasons and/or it could be associated with the smaller size than other seasons. The high RMSE can be explained, since it is well-known that over vegetated/forest areas and the presence of snow/ice, soil moisture retrievals are very problematic for the operational products retrieval accuracy. In addition, it could be due to the difference in the content of soil moisture that can be measured at the thin soil layer that was sampled by ASCAT $(\sim 0.5-2 \mathrm{~cm})$ and the amount of soil moisture in the deeper layer $(5 \mathrm{~cm})$ observed at the ground stations. This is in agreement with the results of Wigneron et al. [60] \& Wagner et al. [61]. Moreover, in vegetated areas (especially forest), there is an issue with the proper roughness characterization, which influences the accuracy of satellite soil moisture retrievals [62]. Additionally, in terms of attenuation, it is observed more in the case of forest than crop, because of large volume of scattering in the case of the former than the latter [63]. That could be the reason for the high RMSE (ENF, WAS). Overall, trends in product accuracy that are dependent on land cover are clearly evident. Furthermore, the error for most sites is largely as a result of scatter rather than the bias.

The results from this study, although perhaps limited by the relatively small sample size, suggest that agreement of the soil moisture estimates are driven to a certain extent by the seasonal cycle. The latter can be potentially ascribed to the phenological changes of vegetation throughout the year [64]. Changes in vegetation type or growth cause a change in vegetation canopy and hence increase the microwave attenuation, which reduce the overall accuracy in soil moisture retrieval. Theoretically, spring and summer have denser plant canopies when compared to autumn and thus higher signal attenuation hampers satellite sensing, resulting in poorer soil moisture retrieval. Furthermore, dew has a significant effect on passive microwave observations by increasing horizontal brightness, and it is most prominent during summer, spring, and autumn, respectively [65]. On the temporal series comparisons, the ASCAT has shown the temporal characteristics of in situ measurements very well. However, the product underestimated the in situ observation during January to February and overestimates the in situ observations from May to June or August (Figures 5 and 7). One possible cause for the high ASCAT soil moisture predictions during summertime might be that the parameterization of ASCAT retrieval is not an optimal term in the vegetation correction (the seasonal behavior of the vegetation correction term could be reasonable, but the magnitude may not be large enough) over this area [53]. The integration of numerical weather models, meteorological variables, local hydrological models, and information on land cover could also be utilized to more accurately analyze the effect of seasonality on soil moisture estimation [54]. Such an investigation could help in improving the soil moisture retrieval algorithms.

\section{Conclusions}

ASCAT is one of the major satellite EO missions utilized today for global soil moisture estimation. This study evaluated ASCAT data for the years 2010 and 2011 in comparison to in situ observations from the FLUXNET network, aiming to appraise the accuracy of ASCAT data in a variety of ecosystem types across different continents. The direct comparison of ASCAT operational product with in situ SSM observations indicated a moderate performance of the product at the studied sites. The main findings of this study can be summarized, as follows:

(1) Overall, the comparison between the ASCAT product and the in situ measurements of SSM in the $0-5 \mathrm{~cm}$ soil moisture layer is comparable to previous validation studies. The low values of RMSE (usually below $0.1 \mathrm{~m}^{3} \mathrm{~m}^{-3}$ ) for SSM prove that the ASCAT soil moisture products provide valuable information at different land use/land cover and different climatic regions (Tables 2-7 and Figures 1-13). 
(2) ASCAT product mostly displayed dry bias and relatively high RMSE. This result suggests that the vegetation effects must be carefully considered for proper roughness characterization in order to achieve consistent SSM estimates (Tables 2-7).

(3) For the cases examined herein, no definite conclusion is reached regarding the RMSE performance over different seasons, as the RMSE differences in RMSE with the variances shown in Tables 3, 5 and 7 are not statistically significant. Regarding the Pearson's correlation coefficient, the ASCAT data perform better in autumn and winter than in the spring and summer. However, the correlation coefficient considerably varies in the winter (from $21 \%$ to $92 \%$ ). Hence, the strength of this association that is based on only six cases (three different continents and two years of observation) is potentially questionable.

(4) The ASCAT data show better agreement (with respect to RMSE) with in situ data for grasslands than for woody savannas and needleleaf forests. On the other hand, woody savannas perform better in terms of the correlation coefficient.

(5) ASCAT soil moisture products for Australia present a systematic overestimation error. This is not unexpected, since soil moisture retrieval that is based on satellite data is a challenge in the presence of snow or ice.

In summary, our results emphasize how essential it is to validate the magnitude and spatial structure of the uncertainties of any new satellite-based remote sensing product before its use in operational applications. Our study findings are important, as the wide use of the ASCAT operational product globally requires an assessment of its accuracy and validation for different application areas, so that data providers and users can understand the uncertainties that are associated with the data and in what applications the product is most suitable.

Author Contributions: Methodology Development \& Implementation, Data Acquisition, and Analysis: S.L.; A.P.; G.P.P.; Writing \& Revision: lead by K.A.K.D. with contributions from all other co-authors.

Funding: The contribution of D.A.K.D. and Y.B. was supported by Projects of International Cooperation and Exchanges NSFC (NSFC-RCUK_STFC) (61661136005), the National Key Research and development Program of China (2016YFA0600703), "Six Talents Peak" high-level talent project in Jiangsu Province (2015-JY-013), and Projects of Key Laboratory of Radiometric Calibration and Validation for Environmental Satellites National Satellite Meteorological Center, China Meteorological Administration. G.P.P.'s participation was supported financially by the European Union's Horizon 2020 Marie Skłodowska-Curie Project "ENViSIoN-EO" (grant agreement No 752094). Sincere thanks also go to Matthew North who helped with the data collection and initial data analysis.

Acknowledgments: All authors wish to thank EUMETSAT for the provision of the ASCAT satellite data and also the FLUXNET network for the in situ data used in the present study.

Conflicts of Interest: The authors declare no conflict of interest.

\section{References}

1. Petropoulos, G.P.; Ireland, G.; Barrett, B. Surface soil moisture retrievals from remote sensing: Current status, products \& future trends. Phys. Chem. Earth Parts A/B/C 2015, 83-84, 36-56.

2. Panegrossi, G.; Ferretti, R.; Pulvirenti, L.; Pierdicca, N. Impact of ASAR soil moisture data on the MM5 precipitation forecast for the Tanaro flood event of April 2009. Nat. Hazards Earth Syst. Sci. 2011, 11, 3135-3149. [CrossRef]

3. Brocca, S.; Moramarco, L.; Melone, T.; Wagner, F.; Hasenauer, W.; Hahn, S. Assimilation of surface- and root-zone ASCAT soil moisture products into rainfall-runoff modeling. IEEE Trans. Geosci. Remote Sens. 2012, 50, 2542-2555. [CrossRef]

4. Bao, Y.; Lin, L.; Wu, S.; Deng, K.A.K.; Petropoulos, G.P. Surface soil moisture retrievals over partially vegetated areas from the synergy of Sentinel-1 and Landsat 8 data using a modified water-cloud model. Int. J. Appl. Earth Obs. Geoinf. 2018, 72, 76-85. [CrossRef]

5. Vogel, M.M.; Orth, R.; Cheruy, F.; Hagemann, S.; Lorenz, R.; Hurk, B.J.; Seneviratne, S.I. Regional amplification of projected changes in extreme temperatures strongly controlled by soil moisture-temperature feedbacks. Geophys. Res. Lett. 2017, 44, 1511-1519. [CrossRef] 
6. Wanders, N.; Karssenberg, D.; de Roo, A.; de Jong, S.M.; Bierkens, M.F.P. The suitability of remotely sensed soil moisture for improving operational flood forecasting. Hydrol. Earth Syst. Sci. 2014, 18, 2343-2357. [CrossRef]

7. Brocca, L.; Tarpanelli, A.; Filippucci, P.; Dorigo, W.; Zaussinger, F.; Gruber, A.; Fernández-Prieto, D. How much water is used for irrigation? A new approach exploiting coarse resolution satellite soil moisture products. Int. J. Appl. Earth Obs. Geoinf. 2018, 73, 752-766. [CrossRef]

8. Vereecken, H.; Huisman, J.A.; Bogena, H.; Vanderborght, J.; Vrugt, J.A.; Hopmans, J.W. On the value of soil moisture measurements in vadose zone hydrology: A review. Water Resour. Res. 2008, 44, 1-21. [CrossRef]

9. Corradini, C. Soil moisture in the development of hydrological processes and its determination at different spatial scales. J. Hydrol. 2014, 516, 1-5. [CrossRef]

10. Seneviratne, S.I.; Wilhelm, M.; Stanelle, T.; van den Hurk, B.; Hagemann, S.; Berg, A.; Cheruy, F.; Higgins, M.E.; Meier, A.; Brovkin, V. Impact of soil moisture-climate feedbacks on CMIP5 projections: First results from the GLACE-CMIP5 experiment. Geophys. Res. Lett. 2013, 40, 5212-5217. [CrossRef]

11. May, W.; Rummukainen, M.; Chéruy, F.; Hagemann, S.; Meier, A. Contributions of soil moisture interactions to future precipitation changes in the GLACE-CMIP5 experiment. Clim. Dyn. 2017, 49, 1681-1704. [CrossRef]

12. Gwak, Y.; Kim, S. Factors affecting soil moisture spatial variability for a humid forest hillslope. Hydrol. Process. 2017, 31, 431-445. [CrossRef]

13. Song, Y.; Guo, W.; Zhang, Y. Numerical study of impacts of soil moisture on the diurnal and seasonal cycles of sensible/latent heat fluxes over semi-arid region. Adv. Atmos. Sci. 2009, 26, 319-326. [CrossRef]

14. Piles, M.; Petropoulos, G.P.; Sánchez, N.; González-Zamora, Á.; Ireland, G. Towards improved spatio-temporal resolution soil moisture retrievals from the synergy of SMOS and MSG SEVIRI spaceborne observations. Remote Sens. Environ. 2016, 180, 403-417. [CrossRef]

15. Petropoulos, G.; Griffiths, H.; Dorigo, W.; Xaver, A.; Gruber, A. Surface Soil Moisture Estimation. In Remote Sensing of Energy Fluxes and Soil Moisture Content; CRC Press: Boca Raton, FL, USA, 2013; pp. 29-48.

16. Petropoulos, G.P.; McCalmont, J.P. An operational in situ soil moisture \& soil temperature monitoring network for West Wales, UK: The WSMN network. Sensors 2017, 17, 1481.

17. Srivastava, P.K.; Petropoulos, G.P.; Kerr, Y.H. Satellite Soil Moisture Retrieval: Techniques and Applications; Elsevier: Amsterdam, The Netherlands, 2016.

18. Petropoulos, G.P.; Srivastava, P.K.; Ferentinos, K.P.; Hristopoulos, D. Evaluating the capabilities of optical/TIR imagine sensing systems for quantifying soil water content. Geocarto Int. 2018. [CrossRef]

19. Kerr, Y.H. Soil moisture from space: Where are we? Hydrogeol. J. 2007, 15, 117-120. [CrossRef]

20. Petropoulos, G.P.; Srivastava, P.K.; Piles, M.; Pearson, S. Earth observation-based operational estimation of soil moisture and evapotranspiration for agricultural crops in support of sustainable water management. Sustainability 2018, 10, 181. [CrossRef]

21. Entekhabi, D.; Jackson, T.J.; Njoku, E.; O'neill, P.; Entin, J. Soil moisture active/passive (SMAP) mission concept. In Proceedings of the Atmospheric and Environmental Remote Sensing Data Processing and Utilization IV: Readiness for GEOSS II, San Diego, CA, USA, 10 September 2008. [CrossRef]

22. Su, C.H.; Ryu, D.; Young, R.I.; Western, A.W.; Wagner, W. Inter-comparison of microwave satellite soil moisture retrievals over the Murrumbidgee Basin, southeast Australia. Remote Sens. Environ. 2013, 134, 1-11. [CrossRef]

23. Kerr, Y.H.; Waldteufel, P.; Wigneron, J.P.; Martinuzzi, J.M.; Font, J.; Berger, M. Soil moisture retrieval from space: The Soil Moisture and Ocean Salinity (SMOS) mission. IEEE Trans. Geosci. Remote Sens. 2001, 39, 1729-1735. [CrossRef]

24. Wagner, W.; Hahn, S.; Kidd, R.; Melzer, T.; Bartalis, Z.; Hasenauer, S.; Figa-Saldaña, J.; de Rosnay, P.; Jann, A.; Schneider, S.; et al. The ASCAT soil moisture product: A review of its specifications, validation results, and emerging applications. Meteorol. Z. 2013, 22, 5-33. [CrossRef]

25. Liu, Y.Y.; Parinussa, R.M.; Dorigo, W.A.; De Jeu, R.A.; Wagner, W.; Van Dijk, A.I.; McCabe, M.F.; Evans, J.P. Developing an improved soil moisture dataset by blending passive and active microwave satellite-based retrievals. Hydrol. Earth Syst. Sci. 2011, 15, 425-436. [CrossRef]

26. Draper, C.S.; Reichle, R.H.; de Lannoy, G.J.M.; Liu, Q. Assimilation of passive and active microwave soil moisture retrievals. Geophys. Res. Lett. 2012, 39. [CrossRef] 
27. Albergel, C.; Rüdiger, C.; Carrer, D.; Calvet, J.C.; Fritz, N.; Naeimi, V.; Bartalis, Z.; Hasenauer, S. An evaluation of ASCAT surface soil moisture products with in-situ observations in Southwestern France. Hydrol. Earth Syst. Sci. 2009, 13, 115-124. [CrossRef]

28. Dorigo, W.; Scipal, K.; Parinussa, R.M.; Liu, Y.Y.; Wagner, W.; De Jeu, R.A.; Naeimi, V. Error characterisation of global active and passive microwave soil moisture data sets. Hydrol. Earth Syst. Sci. 2010, 14, 2605-2616. [CrossRef]

29. Parinussa, R.M.; Holmes, T.R.H.; Wanders, N.; Dorigo, W.A.; de Jeu, R.A.M. A Preliminary Study toward Consistent Soil Moisture from AMSR2. J. Hydrometeorol. 2015, 16, 932-947. [CrossRef]

30. Cui, Y.; Long, D.; Hong, Y.; Zeng, C.; Zhou, J.; Han, Z.; Liu, R.; Wan, W. Validation and reconstruction of FY-3B/MWRI soil moisture using an artificial neural network based on reconstructed MODIS optical products over the Tibetan Plateau. J. Hydrol. 2016, 543, 242-254. [CrossRef]

31. Petropoulos, G.P.; Ireland, G.; Srivastava, P.K. Evaluation of the Soil Moisture Operational Estimates From SMOS in Europe: Results Over Diverse Ecosystems. IEEE Sens. J. 2015, 15, 5243-5251. [CrossRef]

32. Crow, W.T.; Yilmaz, M.T. The Auto-Tuned Land Data Assimilation System (ATLAS). Water Resour. Res. 2014, 50, 371-385. [CrossRef]

33. Bartalis, Z.; Wagner, W.; Naeimi, V.; Hasenauer, S.; Scipal, K.; Bonekamp, H.; Figa, J.; Anderson, C. Initial soil moisture retrievals from the METOP-A Advanced Scatterometer (ASCAT). Geophys. Res. Lett. 2007, 34, L20401. [CrossRef]

34. Wanders, N.; Karssenberg, D.; Bierkens, M.; Parinussa, R.; de Jeu, R.; van Dam, J.; de Jong, S. Observation uncertainty of satellite soil moisture products determined with physically-based modeling. Remote Sens. Environ. 2012, 127, 341-356. [CrossRef]

35. Al-Yaari, A.; Wigneron, J.P.; Ducharne, A.; Kerr, Y.; De Rosnay, P.; De Jeu, R.; Govind, A.; Al Bitar, A.; Albergel, C.; Munoz-Sabater, J. Global-scale evaluation of two satellite-based passive microwave soil moisture datasets (SMOS and AMSR-E) with respect to Land Data Assimilation System estimates. Remote Sens. Environ. 2014, 149, 181-195. [CrossRef]

36. Rötzer, K.; Montzka, C.; Bogena, H.; Wagner, W.; Kerr, Y.H.; Kidd, R.; Vereecken, H. Catchment scale validation of SMOS and ASCAT soil moisture products using hydrological modeling and temporal stability analysis. J. Hydrol. 2014, 519, 934-946. [CrossRef]

37. Rötzer, K.; Montzka, C.; Vereecken, H. Spatio-temporal variability of global soil moisture products. J. Hydrol. 2015, 522, 187-202. [CrossRef]

38. Brocca, L.; Melone, F.; Moramarco, T.; Wagner, W.; Hasenauer, S. ASCAT soil wetness index validation through in situ and modeled soil moisture data in central Italy. Remote Sens. Environ. 2010, 114, 2745-2755. [CrossRef]

39. Parrens, M.; Zakharova, E.; Lafont, S.; Calvet, J.C.; Kerr, Y.; Wagner, W.; Wigneron, J.P. Comparing soil moisture retrievals from SMOS and ASCAT over France. Hydrol. Earth Syst. Sci. 2012, 16, 423-440. [CrossRef]

40. Leroux, D.J.; Kerr, Y.H.; Al Bitar, A.; Bindlish, R.; Jackson, T.J.; Berthelot, B.; Portet, G. Comparison between SMOS, VUA, ASCAT, and ECMWF soil moisture products over four watersheds in U.S. IEEE Trans. Geosci. Remote Sens. 2014, 52, 1562-1571. [CrossRef]

41. Baldocchi, D.D.; Valentini, R.; Running, S.; Oechel, W.; Dhalman, R. Strategies for measuring and modeling $\mathrm{CO}_{2}$ and water vapor fluxes over terrestrial ecosystems. Glob. Chang. Biol. 1995, 2, 159-168. [CrossRef]

42. Wagner, W.; Lemoine, G.; Rott, H. A method for estimating soil moisture from ERS Scatterometer and soil data. Remote Sens. Environ. 1999, 70, 191-207. [CrossRef]

43. Naeimi, V.; Scipal, K.; Bartalis, Z.; Hasenauer, S.; Wagner, W. An improved soil moisture retrieval algorithm for ERS and METOP scatterometer observations. IEEE Trans. Geosci. Remote Sens. 2009, 47, 1999-2013. [CrossRef]

44. Petropoulos, G.P.; Ireland, G.; Srivastava, P.K.; Ioannou-Katidis, P. An appraisal of the accuracy of operational soil moisture estimates from SMOS MIRAS using validated in situ observations acquired in a Mediterranean environment. Int. J. Remote Sens. 2014, 35, 5239-5250. [CrossRef]

45. Lacava, T.; Brocca, L.; Faruolo, M.; Matgen, P.; Moramarco, T.; Pergola, N.; Tramutoli, V. A multi-sensor (SMOS, AMSR-E and ASCAT) satellite-based soil moisture products inter-comparison. In Proceedings of the 2012 IEEE International Geoscience and Remote Sensing Symposium, Munich, Germany, 22-27 July 2012; pp. 1135-1138. 
46. Pierdicca, N.; Pulvirenti, L.; Fascetti, F.; Crapolicchio, R.; Talone, M. Analysis of two years of ASCAT- and SMOS-derived soil moisture estimates over Europe and North Africa. Eur. J. Remote Sens. 2013, 46, 759-773. [CrossRef]

47. Fascetti, F.; Pierdicca, N.; Pulvirenti, L.; Crapolicchio, R. ASCAT and SMOS soil moisture retrievals: A comparison over Europe and Northern Africa. In Proceedings of the 2014 13th Specialist Meeting on Microwave Radiometry and Remote Sensing of the Environment (MicroRad), Pasadena, CA, USA, 24-27 March 2014; Volume 45, pp. 10-13.

48. Brocca, L.; Crow, W.T.; Ciabatta, L.; Massari, C.; De Rosnay, P.; Enenkel, M.; Hahn, S.; Amarnath, G.; Camici, S.; Tarpanelli, A.; et al. A Review of the Applications of ASCAT Soil Moisture Products. IEEE J. Sel. Top. Appl. Earth Obs. Remote Sens. 2017, 10, 2285-2306. [CrossRef]

49. Steele-Dunne, S.C.; Friesen, J.; van de Giesen, N. Using Diurnal Variation in Backscatter to Detect Vegetation Water Stress. IEEE Trans. Geosci. Remote Sens. 2012, 50, 2618-2629. [CrossRef]

50. van Emmerik, T.; Steele-Dunne, S.C.; Judge, J.; van de Giesen, N. Impact of Diurnal Variation in Vegetation Water Content on Radar Backscatter From Maize During Water Stress. IEEE Trans. Geosci. Remote Sens. 2015, 53, 3855-3869. [CrossRef]

51. Brocca, L.; Hasenauer, S.; Lacava, T.; Melone, F.; Moramarco, T.; Wagner, W.; Dorigo, W.; Matgen, P.; Martínez-Fernández, J.; Llorens, P. Soil moisture estimation through ASCAT and AMSR-E sensors: An intercomparison and validation study across Europe. Remote Sens. Environ. 2011, 115, 3390-3408. [CrossRef]

52. Chen, Y.; Yang, K.; Qin, J.; Zhao, L.; Tang, W.; Han, M. Evaluation of AMSR-E retrievals and GLDAS simulations against observations of a soil moisture network on the central Tibetan Plateau. J. Geophys. Res. Atmos. 2013, 118, 4466-4475. [CrossRef]

53. Leroux, D.J.; Kerr, Y.H.; Al Bitar, A.; Bindlish, R.; Jackson, T.J.; Berthelot, B.; Portet, G. Clarifications on the comparison between SMOS, VUA, ASCAT, and ECMWF Soil Moisture Products over Four Watersheds in U.S. IEEE Trans. Geosci. Remote Sens. 2014, 52, 1901-1906. [CrossRef]

54. Srivastava, P.K.; Han, D.; Ramirez, M.A.R.; Islam, T. Appraisal of SMOS soil moisture at a catchment scale in a temperate maritime climate. J. Hydrol. 2013, 498, 292-304. [CrossRef]

55. Loew, A.; Schlenz, F. A dynamic approach for evaluating coarse scale satellite soil moisture products. Hydrol. Earth Syst. Sci. 2011, 15, 75-90. [CrossRef]

56. Qin, J.; Yang, K.; Lu, N.; Chen, Y.; Zhao, L.; Han, M. Spatial upscaling of in-situ soil moisture measurements based on MODIS-derived apparent thermal inertia. Remote Sens. Environ. 2013, 138, 1-9. [CrossRef]

57. Srivastava, P.K. Satellite Soil Moisture: Review of Theory and Applications in Water Resources. Water Resour. Manag. 2017, 31, 3161-3176. [CrossRef]

58. Dorigo, W.A.; Xaver, A.; Vreugdenhil, M.; Gruber, A.; Hegyiova, A.; Sanchis-Dufau, A.D.; Zamojski, D.; Cordes, C.; Wagner, W.; Drusch, M. Global Automated Quality Control of In Situ Soil Moisture Data from the International Soil Moisture Network. Vadose Zone J. 2013, 12. [CrossRef]

59. Al Bitar, A.; Leroux, D.; Kerr, Y.H.; Merlin, O.; Richaume, P.; Sahoo, A.; Wood, E.F. Evaluation of SMOS Soil Moisture Products Over Continental U.S. Using the SCAN/SNOTEL Network. IEEE Trans. Geosci. Remote Sens. 2012, 50, 1572-1586. [CrossRef]

60. Wigneron, J.; Ferrazzoli, P.; Kerr, Y.; Bertuzzi, P. A parametric study on passive and active microwave observations over a soybean crop-Geoscience and Remote Sensing. IEEE Trans. Geosci. Remote Sens. 1999, 37, 2728-2733. [CrossRef]

61. Wagner, W.; Blöschl, G.; Pampaloni, P.; Calvet, J.C.; Bizzarri, B.; Wigneron, J.P.; Kerr, Y. Operational readiness of microwave remote sensing of soil moisture for hydrologic applications. Hydrol. Res. 2007, 38, 1-20. [CrossRef]

62. Srivastava, P.K.; Han, D.; Rico-Ramirez, M.A.; O’Neill, P.; Islam, T.; Gupta, M. Assessment of SMOS soil moisture retrieval parameters using tau-omega algorithms for soil moisture deficit estimation. J. Hydrol. 2014, 519, 574-587. [CrossRef]

63. Krapivin, V.F.; Varotsos, C.A.; Marechek, S.V. The Dependence of the Soil Microwave Attenuation on Frequency and Water Content in Different Types of Vegetation: An Empirical Model. Water. Air. Soil Pollut. 2018, 229, 110. [CrossRef] 
64. Srivastava, P.K.; Han, D.; Rico-Ramirez, M.A.; Al-Shrafany, D.; Islam, T. Data fusion techniques for improving soil moisture deficit using SMOS satellite and WRF-NOAH land surface model. Water Resour. Manag. 2013, 27, 5069-5087. [CrossRef]

65. Du, J.; Jackson, T.J.; Bindlish, R.; Cosh, M.H.; Li, L.; Hornbuckle, B.K.; Kabela, E.D. Effect of dew on aircraft-based passive microwave observations over an agricultural domain. J. Appl. Remote Sens. 2012, 6, 63571. [CrossRef]

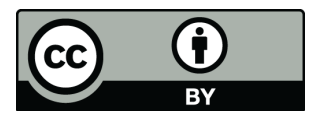

(C) 2019 by the authors. Licensee MDPI, Basel, Switzerland. This article is an open access article distributed under the terms and conditions of the Creative Commons Attribution (CC BY) license (http://creativecommons.org/licenses/by/4.0/). 